\title{
BIOSYNTHESIS OF PROANTHOCYANIDINS IN BARLEY: GENETIC CONTROL OF THE CONVERSION OF DIHYDROQUERCETIN TO CATECHIN AND PROCYANIDINS
}

\author{
by \\ KLAUS NYEGAARD KRISTIANSEN \\ Department of Physiology, Carlsberg Laboratory, \\ Gamle Carlsberg Vej 10, DK-2500 Copenhagen Valby \\ and \\ Institute of Genetics, University of Copenhagen \\ Øster Farimagsgade 2A, DK-1353 Copenhagen K
}

\begin{abstract}
Keywords: Flavonoid biosynthesis, leucocyanidin isomers, ant mutants, genetic control, high pressure liquid chromatography, 'H NMR, mass spectroscopy
\end{abstract}

The conversion of dihydroquercetin to catechin and procyanidin was studied in maturing wild type barley (Hordeum vulgare L., cv. Nordal) seeds and proanthocyanidin free mutants blocked in four different genes, ant 13, ant 17, ant 18 and ant 19. In the wild type barley grown under controlled conditions, maximal rate of synthesis of catechin, procyanidin $\mathrm{B} 3$ and procyanidin $\mathrm{C} 2$ occurred 8-16 days after flowering. Dihydroquercetin was radioactively labelled by feeding $\left(1-{ }^{14} \mathrm{C}\right)$-acetate and $\left(2-{ }^{14} \mathrm{C}\right)$-acetate to flowerbuds of a petunia mutant accumulating this flavonoid. When fed to pericarp-testa tissue of wild type barley labelled catechin, procyanidin B3 and procyanidin $\mathrm{C} 2$ were synthesized establishing dihydroquercetin as a precursor of these compounds. In addition labelled 2,3-trans-3,4-cis-leucocyanidin was synthesized indicating that this compound is an intermediate. The leucocyanidin was identified by co-chromatography with an authentic standard prepared chemically by reduction of dihydroquercetin with $\mathrm{NaBH}_{4}$. The major product of this reduction, however, was the 2,3-trans-3,4-trans-leucocyanidin. Only mutant ant 18-102 accumulated dihydroquercetin in the seeds. Feeding $\left({ }^{14} \mathrm{C}\right)$-dihydroquercetin to pericarp-testa tissue from the mutants revealed that ant 17-139 was capable of synthesizing significant amounts of labelled catechin and procyanidin, whereas ant 13-101, ant 13-152, ant 18-102 and ant 19-109 synthesized none or only very small amounts of these compounds. It is concluded that (i) ant 18 controls the reduction of dihydroquercetin to 2,3-trans-3,4-cis-leucocyanidin, (ii) ant 19 controls the reduction of the leucocyanidin to catechin, and (iii) ant 13 and ant 17 control unidentified steps prior to dihydroquercetin.

Abbreviations: $\mathrm{BAW}=\mathrm{n}$-butanol-acetic acid-water; $\mathrm{BW}=\mathrm{n}$-butanol-water; $\mathrm{CAW}=$ chloroform-acetic acid-water; ' $\mathrm{H} N M R$ = proton nuclear magnetic resonance; $\mathrm{HOAc}=$ acetic acid; $\mathrm{HPLC}=$ high pressure liquid chromatography; $\mathrm{MS}=$ massspectroscopy; sBAWC $=$ s-butanol-acetic acid-water-chloroform; 3,4-cis-diol $=(2 \mathrm{R}, 3 \mathrm{~S}, 4 \mathrm{~S})-3,4,5,7,3^{\prime}, 4^{\prime}$ hexahydroxyflavan; 3,4-trans -diol $=(2 \mathrm{R}, 3 \mathrm{~S}, 4 \mathrm{R})-3,4,5,7,3^{\prime}, 4^{\prime}$-hexahydroxyflavan; $\mathrm{TLC}=$ thin layer chromatography; $\mathrm{UV}=$ ultra violet; $\mathrm{WsB}=$ water saturated s-butanol. 


\section{INTRODUCTION}

Proanthocyanidins (condensed tannins) are widely distributed in the plant kingdom $(21,23)$. Those of barley are located in the seed, and are based exclusively on two flavan-3-ol units, namely (+)-catechin and (+)-gallocatechin, which give rise to procyanidins and prodelphinidins $(29,33,34)$. Their synthesis and that of the anthocyanins in barley are controlled by the ant genes $(27,28,29)$. Nineteen complementing genes, ant 1 to ant 19 , have been identified by JENDE-STRID(28). Mutants in ant 13, ant 17 and ant 18 are blocked in both proanthocyanidin and anthocyanin syntheses, mutants in ant 19 are blocked only in the proanthocyanidin synthises, whereas mutants in ant 1 to ant 12 and ant 14 to ant 16 are blocked only in anthocyanin synthesis (28).

The enzymology of flavonoid biosynthesis is well established from the level of phenylalanine to dihydroquercetin (10). Though these studies have dealt with the biosynthesis of flavonoids other than proanthocyanidins, tracer experiments using phenylalanine (40), cinnamic acid (26), chalcone (35), and dihydrokaempferol (44) have demonstrated that procyanidins are synthesized according to the general scheme for flavonoid formation. Dihydroquercetin is a known precursor of cyanidin (13) and is also believed to be a precursor of catechin and procyanidins $(18,22,23,26,37,39)$, but this has not been confirmed by tracer experiments. Little information is available concerning the biosynthetic steps leading from the presumed dihydroquercetin precursor to catechin and procyanidins. The latter compounds are, however, easily synthesized nonenzymatically by reduction of dihydroquercetin and condensation of the resulting flavan-3,4-diol with catechin in acid (4, $8,9,11)$. Enzymatic reduction of dihydroquercetin to a flavan-3,4-diol has been reported by STAFFORD and LESTER (41).

As a first step toward preparing cell free systems containing the enzymes involved in catechin and procyanidin synthesis, the fate of $\left({ }^{14} \mathrm{C}\right)$-dihydroquercetin fed to seeds of wild type was studied. The results presented establish dihydroquercetin as a precursor of catechin and procyanidins. Furthermore, the sites of action of ant 13 , ant 17 , ant 18 and ant 19 gene products in the biosynthetic pathway were established relative to dihydroquercetin on the basis of dihydroquercetin contents in the mutant seeds and the capabilities of the latter to convert $\left({ }^{14} \mathrm{C}\right)$-dihydroquercetin into catechin and procyanidins.

\section{MATERIALS AND METHODS}

\subsection{Plant materials}

\subsubsection{Barley}

Wild type barley (Hordeum vulgare L., cv. Nordal) and the proanthocyanidin deficient mutants ant 13-101, ant 17-139, ant 18-102 (all induced in Nordal), ant 19-109 (induced in Alf) and ant 13-152 (induced in Triumph) were used in the present study. The barley plants were grown in a Weiss Model $20 \mathrm{RB} / 5$-JU-P growth chamber in continuous light (24,000 lux) supplied by Osram HQI-E, $400 \mathrm{~W} / \mathrm{D}$ lamps under a thermoperiod of 16 hours at $17^{\circ} \mathrm{C}$ and 8 hours at $12{ }^{\circ} \mathrm{C}$.

\subsubsection{Petunia mutant $W 78$}

The white flowering petunia mutant W78 (Petunia hybrida Hort.) is blocked in the biosynthesis of anthocyanins in the petals. The genotype of W78 is anlanl Ht 1Htlhflhflflfl which results in accumulation of dihydroquercetin-7glucosides and dihydroquercetin-4'-glucosides (14, SCHRAM pers. comm.). Seeds of W78 were a kind gift from Dr. A.W. SCHRAM, University of Amsterdam, The Netherlands. The petunia plants were cultivated in a greenhouse, maintained at $20^{\circ} \mathrm{C}$ with supplemental light during the winter months from Osram HQI-E, 400 W/D lamps.

\subsection{Chemicals}

$(+)$-Dihydroquercetin was obtained from Serva (Heidelberg, West Germany). (+)-Catechin and $\mathrm{NaBH}_{4}$ were purchased from Fluka AG (Buchs, Switzerland). $\beta$-Glucosidase isolated from almonds was from Sigma (St. Louis, USA). Sephadex LH-20 was obtained from Pharmacia (Uppsala, Sweden). Sodium $\left(1-{ }^{14} \mathrm{C}\right)$-acetate $(57.0$ $\left.\mathrm{mCi} \times \mathrm{mmol}^{-1}\right)$ and sodium $\left(2-{ }^{14} \mathrm{C}\right)$-acetate $(58.3$ 
$\left.\mathrm{mCi} \cdot \mathrm{mmol}^{-1}\right)$ were purchased from the Radiochemical Centre (Amersham, England). Standards of procyanidin B3 (catechin- $(4 \alpha \rightarrow 8)$ catechin, nomenclature as suggested in ref. 24), procyanidin C2 (catechin- $(4 \alpha \rightarrow 8)$-catechin-( $4 \alpha$ $\rightarrow 8$ )-catechin), prodelphinidin B3 (gallocatechin- $(4 \alpha \rightarrow 8)$-catechin), trimer-1 (gallocatechin-( $4 \alpha \rightarrow 8)$-gallocatechin $(4 \alpha \rightarrow 8)$-catechin) and trimer-2 (gallocatechin-( $4 \alpha \rightarrow 8)$-catechin$(4 \alpha \rightarrow 8)$-catechin), all isolated from barley (33, $34)$, and dihydromyricetin were a kind gift from cand. polyt. H. OUTTRUP, Department of Brewing Chemistry, Carlsberg Research Laboratory.

\subsection{Chromatography}

\subsubsection{High Pressure Liquid Chromatography (HPLC)}

Analyses were performed using a Waters Assoc. (Milford, Mass., USA) instrument composed of two Model 6000A solvent delivery systems, a WISP Model 710B sample injector, a Model 450 wavelength detector, a data module and a Model 720 system controller. Four HPLC systems were used for separation of flavonoids:

I. A $\mu$ Bondapak phenyl column, $30 \mathrm{~cm} \times 3.9$ mm (Waters Assoc.), eluted with a linear gradient from $2 \%$ to $10 \%$ acetic acid in $30 \mathrm{~min}$ and maintained at $10 \%$ acetic acid for $25 \mathrm{~min}$. The flowrate was $1 \mathrm{ml} \cdot \mathrm{min}^{-1}$ (modified from ref. 29).

II. $\mathrm{A} \mu$ Bondapak $\mathrm{C}_{18}$ column, $30 \mathrm{~cm} \times 7.9 \mathrm{~mm}$ (Waters Assoc.), eluted isocratically for $10 \mathrm{~min}$ with methanol:acetic acid:water $(20: 5: 75, \mathrm{v} / \mathrm{v} / \mathrm{v})$ and then isocratically for $20 \mathrm{~min}$ with methanol;acetic acid:water $(40: 5: 55, \mathrm{v} / \mathrm{v} / \mathrm{v})$. The flowrate was $2 \mathrm{ml} \cdot \mathrm{min}^{-1}$.

III. A $\mu$ Bondapak $\mathrm{C}_{18}$ column, $30 \mathrm{~cm} \times 7.9$ $\mathrm{mm}$ (Waters Assoc.), eluted with a linear gradient from methanol:acetic acid:water $(20: 5: 75, \mathrm{v} / \mathrm{v} / \mathrm{v})$ to methanol:acetic acid:water (40:5:55, v/v/v) in 20 min and maintained at the latter for $10 \mathrm{~min}$. The flowrate was $2 \mathrm{ml} \cdot \mathrm{min}^{-1}$.

IV. A $\mu$ Bondapak $C_{18}$ column, $30 \mathrm{~cm} \times 3.9$ $\mathrm{mm}$ (Waters Assoc.), eluted with a linear gradient from $2 \%$ to $10 \%$ acetic acid in $30 \mathrm{~min}$. The flowrate was $2 \mathrm{ml} \cdot \mathrm{min}^{-1}$.

The chromatography was carried out at $20^{\circ} \mathrm{C}$, and elution was monitored spectrophotometri- cally at $280 \mathrm{~nm}$ in all systems. Concentrations of flavonoids were calculated from the peak areas. Table I shows elution volumes of proanthocyanidins and suspected intermediates of proanthocyanidin biosynthesis in the appropriate systems.

\subsubsection{Thin layer chromatography (TLC)}

Analytical separations were performed on Merck (Darmstadt, West Germany) precoated cellulose $F_{254}$ plates $(0.1 \mathrm{~mm})$ unless otherwise stated. Preparative plates $(0.5 \mathrm{~mm})$ were prepared from a slurry of A vicel-cellulose (Merck). The following solvent systems were used for separation of proanthocyanidins and suspected intermediates of proanthocyanidin biosynthesis: (i) CAW, $\mathrm{CHCl}_{3}$ :acetic acid: $\mathrm{H}_{2} \mathrm{O}$ (10:9:1, $\mathrm{v} / \mathrm{v} / \mathrm{v}$ ), (ii) BAW, n-butanol:acetic acid: $\mathrm{H}_{2} \mathrm{O}$ (4:1:5, v/v/v, upper phase), (iii) $15 \%$ acetic acid (HOAc) (v/v), (iv) sBAWC, s-butanol:acetic acid: $\mathrm{H}_{2} \mathrm{O}: \mathrm{CHCl}_{3}(7: 1: 2: 1 \mathrm{v} / \mathrm{v} / \mathrm{v} / \mathrm{v})$, (v) $6 \%$ acetic acid $(\mathrm{HOAc})(\mathrm{v} / \mathrm{v}),(\mathrm{vi}) \mathrm{BW}, \mathrm{n}$-butanol: $\mathrm{H}_{2} \mathrm{O}(7: 2$, v/v), (vii) WsB, $\mathrm{H}_{2} \mathrm{O}$-saturated s-butanol. Pertinent $R_{f}$ values are given in Table $I$.

Flavonoids were visualized under UV-light or by spraying with a mixture of $1 \%(\mathrm{w} / \mathrm{v})$ $\mathrm{FeCl}_{3} \times 6 \mathrm{H}_{2} \mathrm{O}$ and $1 \%(\mathrm{w} / \mathrm{v}) \mathrm{K}_{3} \mathrm{Fe}(\mathrm{CN})_{6}(1: 1, \mathrm{v} / \mathrm{v})$ which produces a blue color with most phenolics (38). Catechin and proanthocyanidins were also detected by spraying with a mixture of $5 \%(\mathrm{w} / \mathrm{v})$ vanillin in ethanol and concentrated $\mathrm{HCl}(4: 1$, $\mathrm{v} / \mathrm{v}$ ) which produces a red color with these compounds (32).

\subsection{Determination of catechin and proanthocyanidin content in maturing wild type barley seeds}

Spikes were collected at regular intervals after flowering, the awns were cut off, and the spikes were frozen in liquid nitrogen and stored at -20 ${ }^{\circ} \mathrm{C}$ until used for extraction similar to that in ref. 29. 50 seeds $(0.57-5.0 \mathrm{~g})$ from each developmental stage were homogenized with a Polytron Type PT 10-35 homogenizer in $25 \mathrm{ml} 75 \%$ $(v / v)$ aqueous acetone. The slurry was centrifuged for $10 \mathrm{~min}$ at $25,000 \times \mathrm{g}$ and the pellet reextracted twice with $25 \mathrm{ml} 75 \%$ acetone. The combined extracts were filtered and delipidated 
K.N. KRISTIANSEN: Biosynthesis of catechin and procyanidins

Table I.

Elution volumes on HPLC and $R_{f}$ values on TLC of proanthocyanidins and suspected intermediates of proanthocyanidin biosynthesis. The chromatographic systems are detailed in section 2.3 .

\begin{tabular}{|c|c|c|c|c|c|c|c|c|c|c|c|}
\hline \multirow{3}{*}{ Flavonoid } & \multicolumn{4}{|c|}{ Elution volume $(\mathrm{ml})$} & \multicolumn{7}{|c|}{$R_{f}$ value } \\
\hline & & & & & & & $15 \%$ & & $6 \%$ & & \\
\hline & I & II & III & IV & CAW & BAW & HOAC & sBAWC & HOAC & BW & WsB \\
\hline Catechin & 25.2 & - & - & 24.4 & - & 0.71 & - & 0.66 & - & - & - \\
\hline Procyanidin B3 & 23.4 & - & - & 19.9 & - & - & - & 0.44 & - & - & - \\
\hline Procyanidin $\mathrm{C} 2$ & 29.3 & - & - & 21.3 & - & - & - & 0.33 & - & - & - \\
\hline \multicolumn{12}{|c|}{ 2,3-trans-3,4-trans- } \\
\hline $\begin{array}{l}\text { Leucocyanidin } \\
\text { 2,3-trans-3,4-cis- }\end{array}$ & - & - & - & 21.6 & - & 0.69 & - & 0.61 & 0.46 & 0.59 & 0.71 \\
\hline Leucocyanidin & - & - & - & 14.0 & - & 0.69 & - & 0.48 & 0.45 & 0.48 & 0.58 \\
\hline Dihydroquercetin & - & 40.2 & 29.7 & 49.9 & 0.34 & 0.84 & 0.53 & 0.86 & - & - & - \\
\hline Dihydromyricetin & - & - & - & 29.4 & - & - & - & 0.75 & - & - & - \\
\hline Prodelphinidin B3 & - & - & - & 12.6 & - & - & - & 0.32 & - & - & - \\
\hline Trimer- 1 & - & - & - & 11.3 & - & - & - & 0.14 & - & - & - \\
\hline Trimer-2 & - & - & - & 15.5 & - & - & - & 0.24 & - & - & - \\
\hline
\end{tabular}

with $3 \times 25 \mathrm{ml}$ petroleum ether (bp. $40-60{ }^{\circ} \mathrm{C}$ ). The acetone was removed from the extract in vacuo at $30{ }^{\circ} \mathrm{C}$. Five $\mathrm{ml} 96 \%$ ethanol was added to prevent precipitation and the volume was adjusted to $25 \mathrm{ml}$ with water. $100 \mu \mathrm{l}$ was subjected to HPLC analysis in system I (section 2.3.l) and the concentrations of catechin, procyanidin B3 and procyanidin C2 were calculated from peak areas. The identities of peaks were confirmed by the vanillin test (section 2.10 ) and by the conversion of procyanidins to cyanidin upon hydrolysis (section 2.10).

\subsection{Isolation of dihydroquercetin from barley seeds}

Wild type, ant 13-101, ant 17-139, ant 18-102 and ant 19-109 seeds (28 days after flowering) were assayed for the presence of dihydroquercetin. 200 seeds were homogenized with the Polytron in $100 \mathrm{ml}$ acetone. The slurry was centrifuged for $10 \mathrm{~min}$ at $20,000 \times \mathrm{g}$ and the pellet was reextracted twice with $50 \mathrm{ml}$ acetone. The combined extracts were filtered and evaporated to dryness in vacuo at $30^{\circ} \mathrm{C}$. The residue was dissolved in $10 \mathrm{ml}$ methanol and hydrolyzed with $10 \mathrm{ml} 2 \mathrm{M}-\mathrm{HCl}$ for $15 \mathrm{~min}$ at $100{ }^{\circ} \mathrm{C}$ to produce the aglucone. The hydrolysate was extracted with ether $(4 \times 20 \mathrm{ml})$. The ether extracts were dried over $\mathrm{Na}_{2} \mathrm{SO}_{4}$ and evaporated to dryness in vacuo at $30^{\circ} \mathrm{C}$. The residue was dissolved in methanol and applied to a preparative TLC cellulose plate $(0.5 \mathrm{~mm})$ which was developed in $\mathrm{CAW}$. The zone corresponding to dihydroquercetin was scraped off and the gel eluted with methanol $(3 \times 5 \mathrm{ml})$. After concentration to 400 $\mu \mathrm{l}$ an aliquot was subjected to HPLC analysis using system II (section 2.3.1).

\subsection{Synthesis and isolation of $\left({ }^{14} \mathrm{C}\right)$-dihydro- quercetin}

$\left({ }^{14} \mathrm{C}\right)$-Dihydroquercetin was prepared by feeding ${ }^{14} \mathrm{C}$-labelled acetate to excised flowerbuds of the dihydroquercetin accumulating petunia mutant W78. 25 buds were surface sterilized and dissected as described by $\mathrm{KHO}$ et al. (31). The corollas were incubated in a petri dish $(90 \times 15$ $\mathrm{mm}$ ) with $10 \mathrm{ml}$ petunia culture medium (31) containing $1 \mathrm{mCi}$ sodium $\left(1-{ }^{14} \mathrm{C}\right)$-acetate and 1 $\mathrm{mC}$ i sodium $\left(2-{ }^{14} \mathrm{C}\right)$-acetate. The incubation was carried out for 24 hours at $24^{\circ} \mathrm{C}$ and 2,500 lux supplied by an Osram HQI-E, $400 \mathrm{~W} / \mathrm{D}$ lamp.

After incubation the buds were washed with water and homogenized in a mortar. The homogenate was extracted with $75 \%$ acetone $(6 \times 25$ $\mathrm{ml}$ ) and the combined acetone extracts were delipidated with $3 \times 50 \mathrm{ml}$ petroleum ether. The 
extract was concentrated to a $10 \mathrm{ml}$ water phase in vacuo at $30^{\circ} \mathrm{C}$ and hydrolyzed overnight at 20 ${ }^{\circ} \mathrm{C}$ with $3 \mathrm{mg}$ (18.9 units) of $\beta$-glucosidase to produce the aglucone of dihydroquercetin. Dihydroquercetin was extracted into ether $(6 \times 10$ $\mathrm{ml}$ ). The ether extracts were dried over $\mathrm{Na}_{2} \mathrm{SO}_{4}$ and evaporated to dryness in vacuo at $30^{\circ} \mathrm{C}$. The residue was dissolved in $1 \mathrm{ml}$ methanol and the labelled dihydroquercetin was finally purified by semi-preparative HPLC using system III (section 2.3.1). After removal of methanol in vacuo, the combined collected eluates were freezedried. The purified $\left({ }^{14} \mathrm{C}\right)$-dihydroquercetin was dissolved in methanol and stored at $-20{ }^{\circ} \mathrm{C}$.

\subsection{Chemical synthesis of leucocyanidins}

2.7.1. Synthesis and isolation of two isomeric

\section{flavan-3,4-diols}

Leucocyanidins $(3,4,5,7,3$ ', 4 '-hexahydroxyflavans) were synthesized by reduction of dihydroquercetin $(0.5 \mathrm{~g})$ with $\mathrm{NaBH}_{4}(0.25 \mathrm{~g})$, and purified by chromatography on a Sephadex LH-20 column using ethanol, as described in detail by PORTER and FOO (36). Elution was followed by subjecting aliquots of the fractions to TLC analysis in 6\% HOAc and HPLC analysis using system IV (section 2.3.1). The major 2,3-trans-3,4-trans-leucocyanidin isomer $((2 \mathrm{R}$, 3S,4R)-3,4,5,7,3',4'-hexahydroxyflavan $=3,4$ trans-diol), also isolated by PORTER and FOO, eluted in fractions 22-39. After concentration of the pooled fractions in vacuo at $30^{\circ} \mathrm{C}$ and rechromatography, a pure preparation of the 3,4-trans-diol was obtained, as judged from HPLC and TLC analyses.

A minor 2,3-trans-3,4-cis-leucocyanidin isomer $\left((2 \mathrm{R}, 3 \mathrm{~S}, 4 \mathrm{~S})-3,4,5,7,3^{\prime}, 4^{\prime}\right.$ '-hexahydroxyflavan $=3,4$-cis -diol), not isolated by PORTER and Foo, eluted in fractions 15-22. Fractions 15-19 were pooled and concentrated in vacuo at $30^{\circ} \mathrm{C}$. HPLC using system IV revealed only a few minor contaminating peaks. TLC analysis, however, showed the presence of many prominent components having greater $R_{r}$ values than the 3,4-cis-diol and giving a positive reaction with the vanillin reagent. The 3,4-cis-diol was further purified by HPLC using system IV and immediately freeze-drying the eluate. Recoveries of $70-90 \%$ were obtained in this way. The final preparation of the 3,4-cis-diol contained only a few minor, vanillin positive contaminants that migrated more slowly than the 3,4-cis-diol on TLC plates developed in BW and WsB (section 2.3.2). Presumably they are self-condensation products of the 3,4-cis-diol.

\subsubsection{Methylation of leucocvanidins}

To obtain 5,7,3',4'-tetramethyl ethers of the leucocyanidins needed for mass spectroscopy (MS), the two 3,4-diols were separately dissolved in methanol and methylated with an excess of diazomethane in ether for 48 hours at $-15^{\circ} \mathrm{C}$. The reaction mixture was then evaporated to dryness under a stream of $N_{2}$. The residue was dissolved in acetone and applied to a Merck precoated kieselgel $60 \mathrm{~F}_{254}$ plate $(0.25 \mathrm{~mm})$ which was developed in benzene:acetone $(4: 1, v / v)$ (36). The methylation resulted in one major UV-absorbing band for each 3,4-diol. $R_{f}$ values of 0.17 and 0.22 were obtained for the tetramethyl ether of the 3,4-trans- and 3,4-cis-diols, respectively. The tetramethyl ethers were eluted from TLC plates with acetone.

\subsubsection{Condensation of the 3,4-cis-diol with catechin}

To $124 \mathrm{nmol}\left({ }^{14} \mathrm{C}\right)$-catechin $(5,300 \mathrm{cpm})$ in 1 ml water was added $37.5 \mathrm{nmol} 2,3$-trans $-3,4$-cisleucocyanidin in five $\mu \mathrm{l}$ methanol. The mixture was acidified to $\mathrm{pH} 1.2$ with $10 \mu \mathrm{l} 8 \mathrm{M}-\mathrm{HCl}$ and incubated for 1 hour at room temperature. The flavonoids were extracted into ethyl acetate $(5 \times 1$ $\mathrm{ml}$ ). The combined extracts were dried over $\mathrm{Na}_{2} \mathrm{SO}_{4}$ and evaporated to dryness under a stream of $\mathrm{N}_{2}$. The residue was dissolved in methanol and applied to a TLC plate which was developed in SBAWC (section 2.3.2). The plate was scanned for radioactivity and the radioactive products formed were identified as described in section 2.8. A control lacking the 3,4-cis-diol was included.

\subsection{Administration of $\left({ }^{14} \mathrm{C}\right)$-dihydroquercetin to barley seeds and isolation of labelled products \\ Spikes were harvested 12 days after flowering}


and 25 seeds were picked at random. The tissue consisting of pericarp and testa was isolated manually by removing the husk and squeezing out the endosperm and the adhering aleurone layer. The pericarp-testa tissue $(0.46-0.52 \mathrm{~g})$ was incubated in a $25 \mathrm{ml}$ Erlenmeyer flask in $2 \mathrm{ml}$ $1 \mathrm{mM}$-chloramphenicol solution containing 1 $\mu \mathrm{Ci}\left({ }^{14} \mathrm{C}\right)$-dihydroquercetin $\left(2.6 \mathrm{mCi} \cdot \mathrm{mmol}^{-3}\right)$. The incubation lasted 24 hours at $20^{\circ} \mathrm{C}$ during which time 1,700 lux were supplied by an Osram HQI-E, $400 \mathrm{~W} / \mathrm{D}$ lamp.

After incubation the tissue was washed with water and homogenized with the Polytron in $10 \mathrm{ml} 75 \%$ acetone. $100 \mu \mathrm{g}$ catechin, $100 \mu \mathrm{g}$ procyanidin B3, $190 \mu \mathrm{g}$ 3,4-trans-diol and 120 $\mu \mathrm{g} 3,4$-cis-diol in $220 \mu \mathrm{l}$ methanol were added as carriers. The slurry was centrifuged and the pellet extracted with $75 \%$ acetone $(2 \times 5 \mathrm{ml})$. The combined extracts were delipidated with $3 \times 5$ $\mathrm{ml}$ petroleum ether and concentrated to a $5 \mathrm{ml}$ water phase in vacuo at $30^{\circ} \mathrm{C}$. The flavonoids were extracted into ethyl acetate $(4 \times 5 \mathrm{ml})$. The combined ethyl acetate extracts were dried over $\mathrm{Na}_{2} \mathrm{SO}_{4}$ and evaporated to dryness in vacuo at $30{ }^{\circ} \mathrm{C}$. The residue was dissolved in $100 \mu \mathrm{l}$ methanol. Identification of labelled catechin and procyanidins, and quantitation of radioactivity in the products were carried out using two different methods:

(i) $25 \mu \mathrm{l}$ of the final extract was applied to a TLC plate which was developed in SBAWC. The plate was scanned for radioactivity, and the radioactive zones corresponding to catechin, procyanidin B3 and procyanidin C2 were scraped off and the gel eluted with water $(3 \times 2$ $\mathrm{ml}$ ). The samples were freeze-dried and redissolved in methanol. An aliquot was subjected to HPLC using system IV (section 2.3.1). The peaks were collected and counted.

(ii) $25 \mu \mathrm{l}$ of the final extract was subjected to HPLC using system IV. One $\mathrm{ml}$ fractions were collected and counted to localize the radioactivity. Another $25 \mu l$ was then injected, and the appropriate fractions containing the labelled catechin, procyanidin and leucocyanidin peaks were collected. The samples were freeze-dried, dissolved in methanol and identified by TLC using sBAWC as the developing system.

\subsection{Determination of radioactivity}

TLC plates $(5 \times 20 \mathrm{~cm})$ were scanned for radioactivity using a Packard Model 7201 radiochromatogram scanner (Radio-TLC). Samples were counted in $10 \mathrm{ml}$ of a scintillation liquid composed of $7.5 \mathrm{~g}$ 2,5'-diphenyloxazole (PPO), 0.15 g 2,2'-p-phenylen-bis-(5-phenyloxazole) (POPOP), 0.51 Triton $X-100$ per l of xylen using a Beckman LS 3155T liquid scintillation spectrometer. The counting efficiency of ${ }^{14} \mathrm{C}$ was $95.3 \%$.

\subsection{Other analytical methods}

A vanillin reagent consisting of $1 \%(\mathrm{w} / \mathrm{v})$ vanillin in concentrated $\mathrm{HCl}$ was used in a test tube assay to detect catechin and procyanidins (43). Procyanidins were also detected by the production of cyanidin upon hydrolysis with 5 $\mathrm{M}-\mathrm{HCl} /$ ethanol for $20 \mathrm{~min}$ at $80^{\circ} \mathrm{C}$ (29). MS was performed on a VG $7070 \mathrm{~F}$ instrument equipped with a VG 2035 Data System. The samples were inserted directly $\left(200^{\circ} \mathrm{C}, 70 \mathrm{eV}\right)$.

\section{RESULTS}

\subsection{Time course of catechin and procyanidin biosynthesis in maturing wild type barley seeds}

To determine the developmental stage during barley seed maturation where maximal catechin and procyanidin synthesis occur, wild type seeds were collected at four day intervals from the time of flowering to 28 days after flowering when the seeds were physiologically mature. Acetone extracts of the seeds were analysed by HPLC and the concentrations of catechin, procyanidin $\mathrm{B} 3$ and procyanidin $\mathrm{C} 2$ were calculated from the peak areas. Figure 1 shows high pressure liquid chromatograms of acetone extracts of seeds collected 8,16 and 28 days after flowering. The prodelphinidins known to be present in barley $(29,33,34)$ were eluted within the first $22 \mathrm{ml}$. Since they were not satisfactorily separated from other UV-absorbing compounds, they are not included in the time course study.

Figure 2 shows the time course of catechin, procyanidin $\mathrm{B} 3$ and procyanidin $\mathrm{C} 2$ synthesis during seed maturation. Catechin appears in the seeds four days after flowering, increases rapidly 


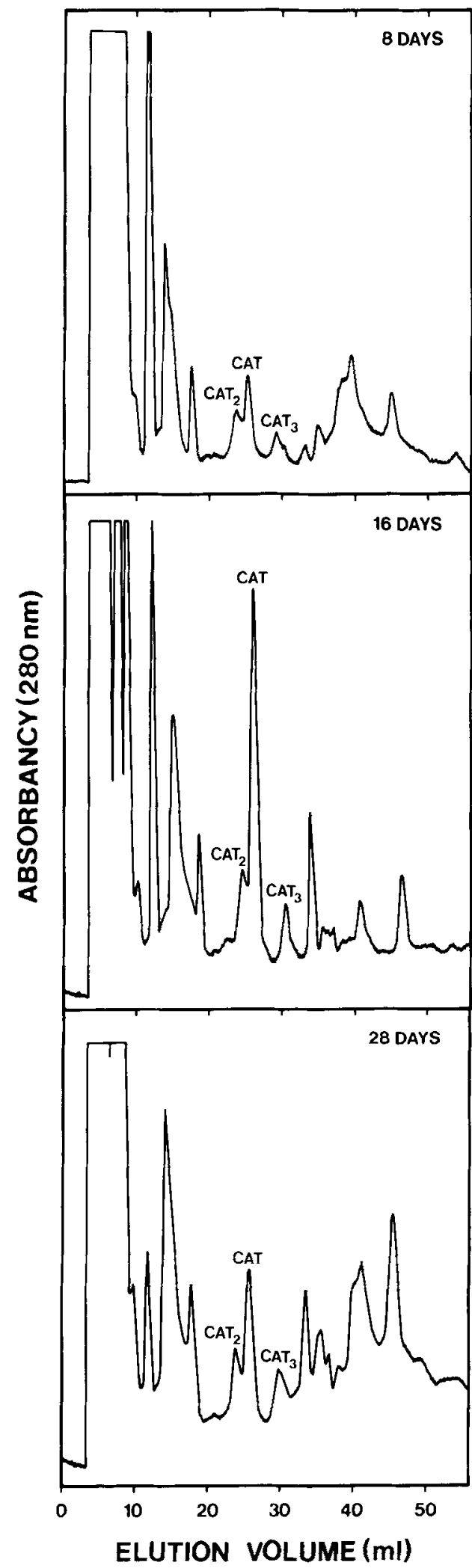

Figure 1 . High pressure liquid chromatograms of acetone extracts of wild type barley seeds harvested 8,16 and 28 days after flowering. Separation was carried out using HPLC system I (section 2.3.I). CAT $=$ catechin, $\mathrm{CAT}_{2}=$ procyanidin $\mathrm{B} 3, \mathrm{CAT}_{3}=$ procya nidin $\mathrm{C} 2$.

and reaches a maximum of approximately 97 nmoles $x$ seed $^{-1} 18$ days after flowering. Then the content of catechin decreases, reaching a constant level of approximately $40 \mathrm{nmoles} \cdot \mathrm{seed}^{-1}$. The procyanidins $\mathrm{B} 3$ and $\mathrm{C} 2$ appear in the seeds 4-8 days after flowering and are synthesized until approximately 20 days after flowering. Then the contents of procyanidin $\mathrm{B} 3$ and procyanidin $\mathrm{C} 2$ remain constant at 9.7 and 4.3 nmoles ' seed $^{-1}$, respectively. The biosyntheses of both catechin, procyanidin $\mathrm{B} 3$ and procyanidin $\mathrm{C} 2$ are in an almost linear phase 8-16 days after flowering and the rates of synthesis are 10,0.9 and 0.5 nmoles $\cdot$ seed $^{-1} \cdot$ day $^{-1}$, respectively. Anthocyanins were visually detected in the husk from the eighth day after flowering.

That catechin appears first in the seed followed by procyanidin $\mathrm{B} 3$ and then procyanidin

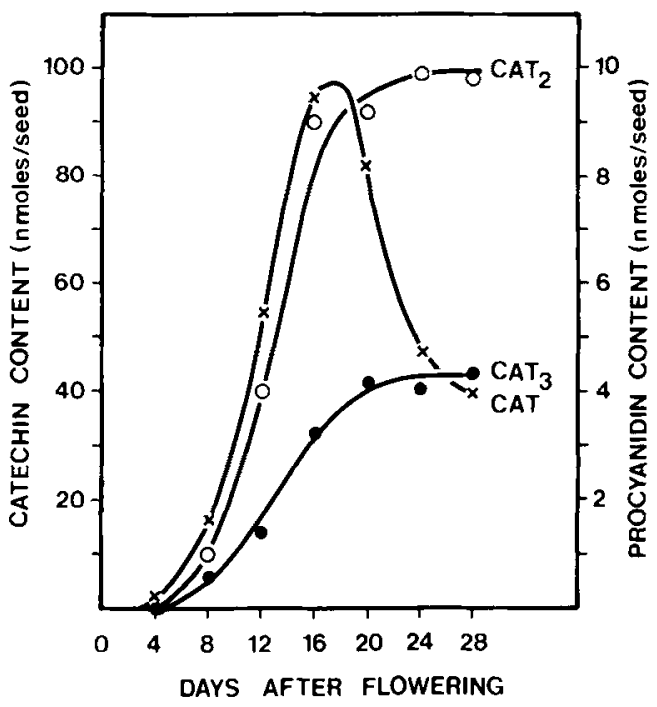

Figure 2. Time course of catechin and procyanidin biosynthesis in maturing wild type seeds. CAT = catechin, $\mathrm{CAT}_{2}=$ procyanidin $\mathrm{B} 3, \mathrm{CAT}_{3}=$ procyanidin C2. 
$\mathrm{C} 2$ is in agreement with the idea that procyanidins in general are synthesized sequentially from monomer through dimer and trimer to higher polymers $(19,23)$.

The observed decline in catechin content after reaching a maximum is in agreement with other time course studies in barley and sorghum. BRANDON et al. (5) investigating field grown barley found that the most significant difference between a sample of seeds where chlorophyll was still present and a mature sample was the relatively high concentration of catechin in the former. In sorghum the decline in catechin content was found to be associated with the synthesis of procyanidins of higher molecular weights $(15,16,19)$. The decrease in catechin concentration observed in the present study, however, was not associated with synthesis of procyanidin oligomers, since the contents of procyanidin B3 and procyanidin $\mathrm{C} 2$ remained constant. No procyanidins consisting of more than three catechin units have been identified in the Nordal barley used $(29,33,34)$. Marked changes in the prodelphinidin content were not detectable during the decline in catechin content. The reason for the decrease in catechin concentration is unknown. Possibly catechin in contrast to the procyanidins is degraded by the plant when the synthesis of procyanidins has stopped. Some evidence exists that flavan-3-ols such as catechin are catabolized in vivo (3). Furthermore, STAFFORD et al. (40) have observed production of ${ }^{14} \mathrm{CO}_{2}$ upon feeding $\left({ }^{14} \mathrm{C}\right)$-catechin to cell cultures of Douglas fir. Another explanation for the apparent decline in catechin content would be that catechin in barley is modified into yet unidentified forms that escape detection with the isolation procedure used, e.g. glucosilated (30) or esterified to gallic acid (42).

In the mature barley seeds, the content of catechin is much greater than that of procyanidin B3 which in turn is twice that of procyanidin C2. The presented data provide only very weak if any support for the proposal (17) that an increase in molecular weight of proanthocyanidins occurs upon tissue maturation. This is in marked contrast to the situation in sorghum where catechin and dimer (epicatechin- $(4 \beta \rightarrow 8)$ catechin) are only present in trace amounts and polymeric procyanidins dominate in mature seeds $(15,16,19)$. This time course study is, however, in agreement with the hypothesis (22) that a steady state concentration of procyanidins is maintained in the vegetative tissues of the plant after an initial burst of procyanidin synthesis.

\subsection{Dihydroquercetin content in wild type and proanthocyanidin free barley mutants}

As a first approach to localize the sites of action of ant 13, ant 17, ant 18 and ant 19 in the biosynthetic pathway to catechin and procyanidins in barley seeds, the genetic blocks were determined relative to the postulated dihydroquercetin intermediate.

Initially, seeds of ant 13-101, ant 17-139, ant 18-102, ant 19-109 and wild type were assayed for the presence of dihydroquercetin as described in section 2.5. HPLC analysis of the extracts (Figure 3) revealed that ant 18-102 was the only mutant accumulating dihydroquercetin and that trace amounts might exist in wild type. The identity of the major HPLC peak in the ant 18-102 sample as dihydroquercetin was confirmed by co-TLC with an authentic standard in CAW, BAW and 15\% HOAc. The content of dihydroquercetin in the ant 18-102 mutant was 2.0 nmoles $\cdot \operatorname{seed}^{-1}$. All was present as glucosides as judged from unhydrolyzed and hydrolyzed samples. The extent of dihydroquercetin accumulation in ant 18-102 is much smaller than expected when compared to the contents of catechin, procyanidin B3 and procyanidin $\mathrm{C} 2$ in wild type seeds of the same developmental stage. Based on catechin units incorporated this content is 72 nmoles ' seed $^{-1}$. Whether the dihydroquercetin synthesized in ant 18-102 seeds is (i) converted into other flavonoid products, e.g. quercetin glucosides, (ii) catabolized, as might be the case for catechin, or (iii) inhibited by an unknown regulatory mechanism which prevents an extensive accumulation of dihydroquercetin is unknown. The small but significant accumulation of dihydroquercetin in a mutant blocked in the biosynthesis of catechin and proanthocyanidins strongly supports the idea that dihydroquercetin 

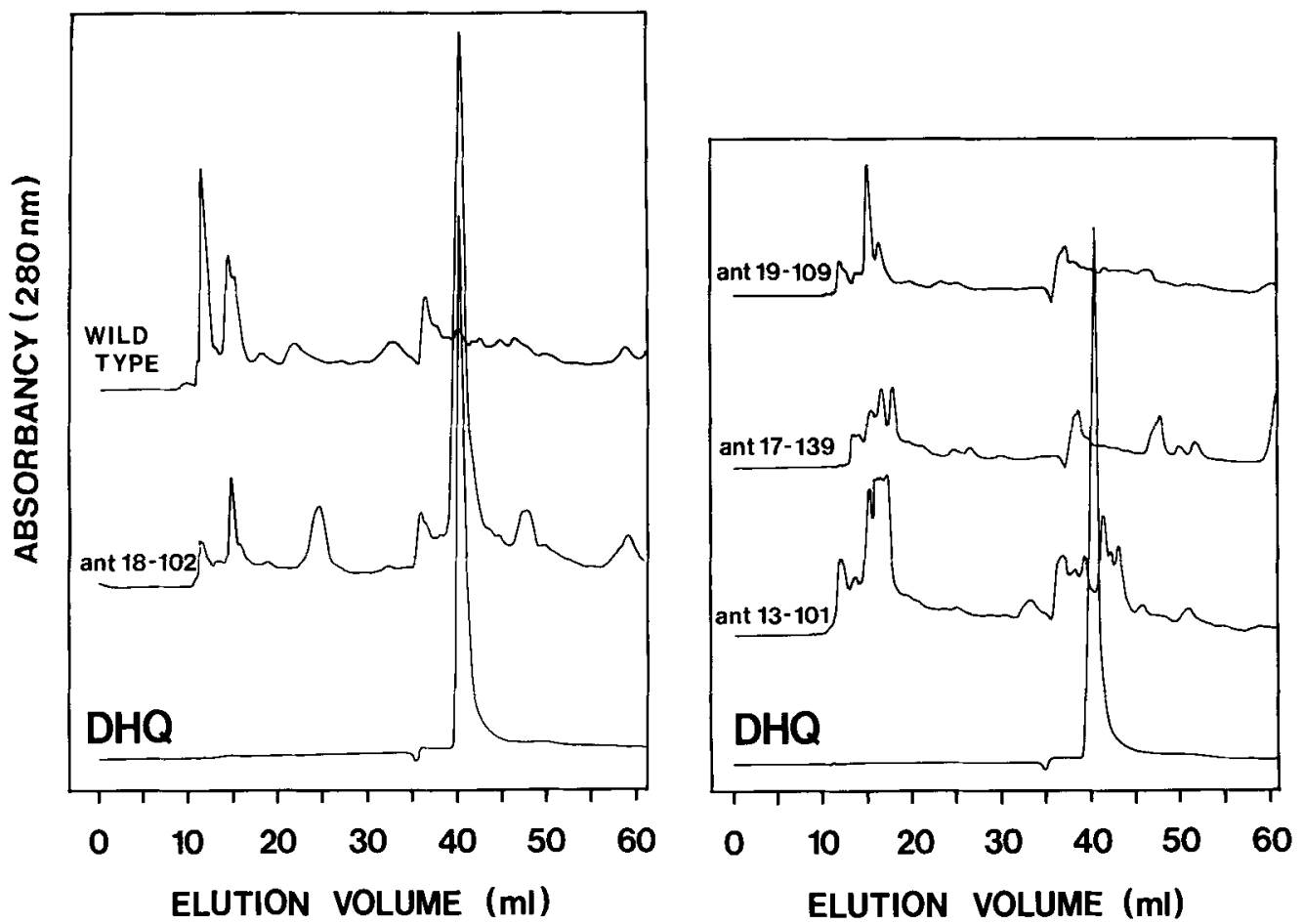

Figure 3. High pressure liquid chromatograms of extracts of wild type, ant 18-102, ant 19-109, ant 17-139 and ant 13-101 seeds harvested 28 days after flowering. Separation was carried out using HPLC system II (section 2.3.l) and injecting $100 \mu \mathrm{l} . \mathrm{DHQ}=$ dihydroquercetin standard.

is an intermediate in the biosynthetic pathway leading to these compounds.

On the basis of the dihydroquercetin measurements, no conclusions can be drawn regarding the sites of action of ant 13-101, ant 17-139 and ant 19-109.

\subsection{Synthesis and identification of $\left({ }^{14} \mathrm{C}\right)$-di- hydroquercetin}

Another way to localize the genetic blockages in the proanthocyanidin free mutants is to establish if any of the mutants are able to convert dihydroquercetin into catechin and procyanidins. For this purpose, and to establish dihydroquercetin as a precursor, $\left({ }^{14} \mathrm{C}\right)$-dihydroquercetin was synthesized.

Ring A of the flavonoid skeleton is formed by a head-to-tail condensation of three molecules of malonyl-CoA which is synthesized from acetate, coenzyme $\mathrm{A}$ and $\mathrm{CO}_{2}(10,18,20)$. $\left({ }^{14} \mathrm{C}\right)$-Dihydroquercetin, uniformly labelled in the A-ring (Figure 4), was thus prepared by feeding $\left(1-{ }^{14} \mathrm{C}\right)$-acetate and $\left(2-{ }^{14} \mathrm{C}\right)$-acetate to flowerbuds of the dihydroquercetin accumulating petunia mutant $W 78$. The buds used were $25-35 \mathrm{~mm}$ in length. At this developmental stage the synthesis of dihydroquercetin has just entered the linear phase and only a small amount of dihydroquercetin is present. Time course studies on the incorporation of $\left({ }^{14} \mathrm{C}\right)$-acetate into

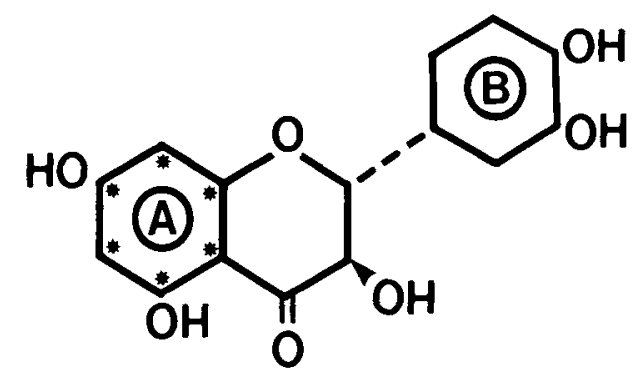

Figure $4 .\left({ }^{14} \mathrm{C}\right)$-dihydroquercetin, uniformly labelled in the A-ring. 


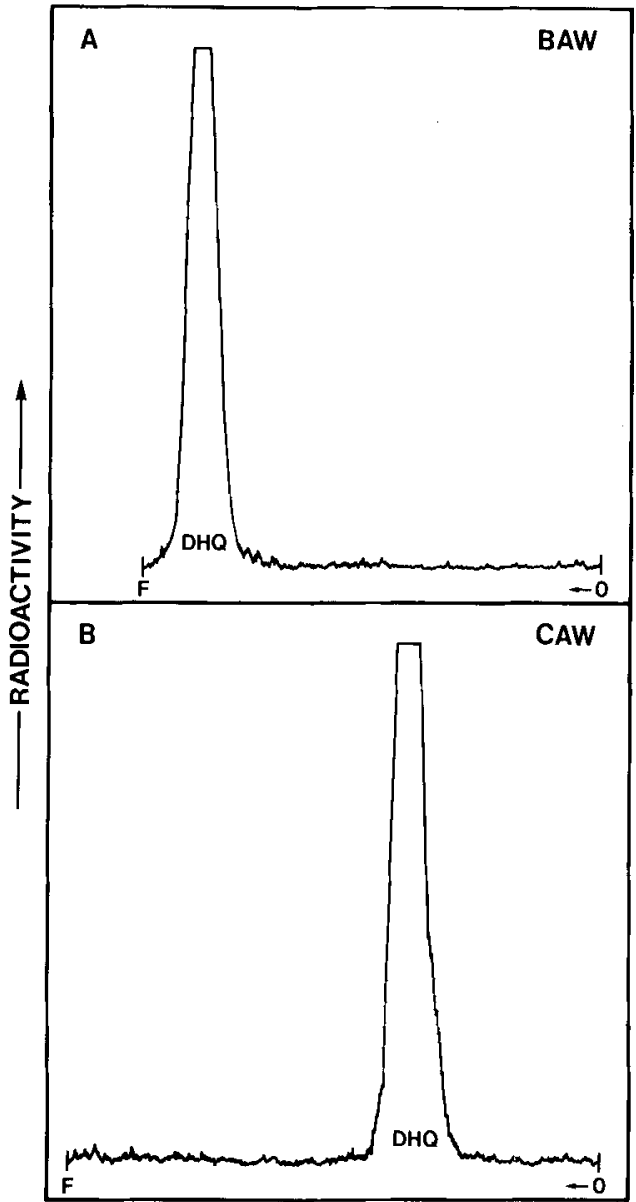

Figure 5. Radio-thin layer chromatograms of the purified $\left({ }^{14} \mathrm{C}\right)$-dihydroquercetin, synthesized by feeding $\left(1-{ }^{14} \mathrm{C}\right)$-acetate and $\left(2-{ }^{14} \mathrm{C}\right)$-acetate to buds of petunia mutant W78. Plates spotted with ca. $200,000 \mathrm{cpm}$ were developed in (A) BAW or (B) CAW (section 2.3.2). $\mathrm{DHQ}=$ dihydroquercetin, $\mathrm{O}=$ origin, $\mathrm{F}=$ solvent front.

dihydroquercetin revealed that an incubation period of 24 hours offered a reasonable compromise between the specific activity of dihydroquercetin, which reached a maximum after approximately 12 hours and then declined, and the total amount of radioactivity incorporated into dihydroquercetin.

25 buds took up $90 \%$ of the radioactivity when incubated for 24 hours with $2 \mathrm{mCi}\left({ }^{14} \mathrm{C}\right)$-acetate. Approximately $40 \%$ of the radioactivity was found in the acetone extracts (see section 2.6), but the majority of this radioactivity was incor- porated into lipids and was removed by extracting with petroleum ether. The yield of purified $\left({ }^{14} \mathrm{C}\right)$-dihydroquercetin ranged from 44 to $52 \mu \mathrm{Ci}$ in three different experiments and specific activities of $2.6,3.1$ and $4.2 \mathrm{mCi} \cdot \mathrm{mmol}^{-1}$ were obtained. The purity of the final $\left({ }^{14} \mathrm{C}\right)$-dihydroquercetin preparation was checked by TLC (Figure 5) and by HPLC (Figure 6). Dihydroquercetin was found to be the only radioactively labelled compound in the preparation, but some minor UV-absorbing compounds were also present having slightly larger elution volumes than dihydroquercetin on HPLC. The labelled compound was simultaneously, conclusively identified as dihydroquercetin by co-chromatography with an authentic standard.

This in vivo synthesis of $\left({ }^{14} \mathrm{C}\right)$-dihydroquercetin seems to be a satisfactory alternative to the in vitro synthesis of labelled flavonoids from $\left(2-{ }^{14} \mathrm{C}\right)$-malonyl-CoA and 4-coumaroyl$\mathrm{CoA}$ (or caffeoyl-CoA), requiring chalcone synthase, chalcone isomerase, flavanone-3-hydroxylase and, if using 4-coumaroyl-CoA, a flavonoid-3'-hydroxylase in addition $(6,12)$.

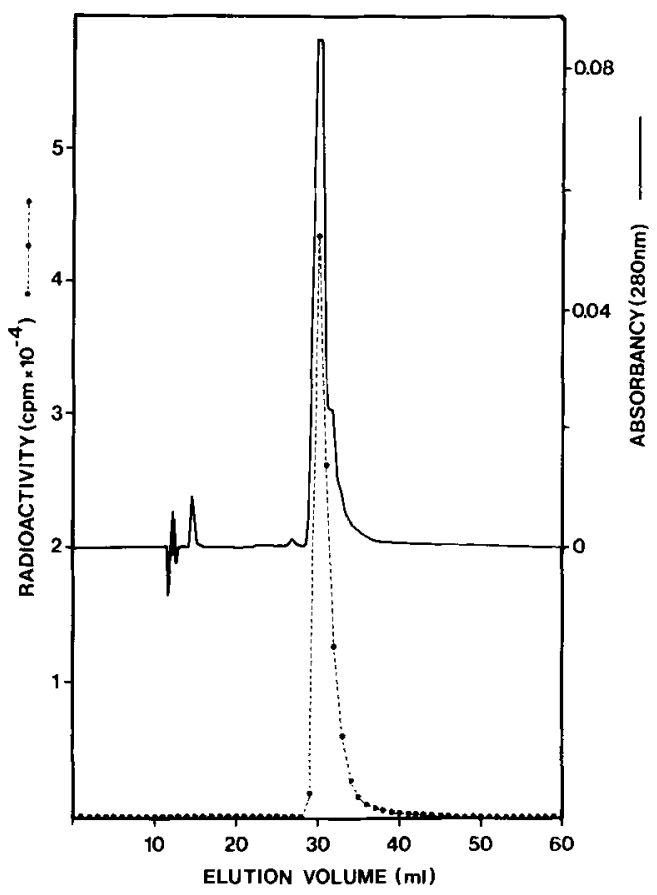

Figure 6. High pressure liquid chromatogram of the purified $\left({ }^{14} \mathrm{C}\right.$ )-dihydroquercetin. HPLC system $\mathrm{III}$ (section 2.3.1) was used. 


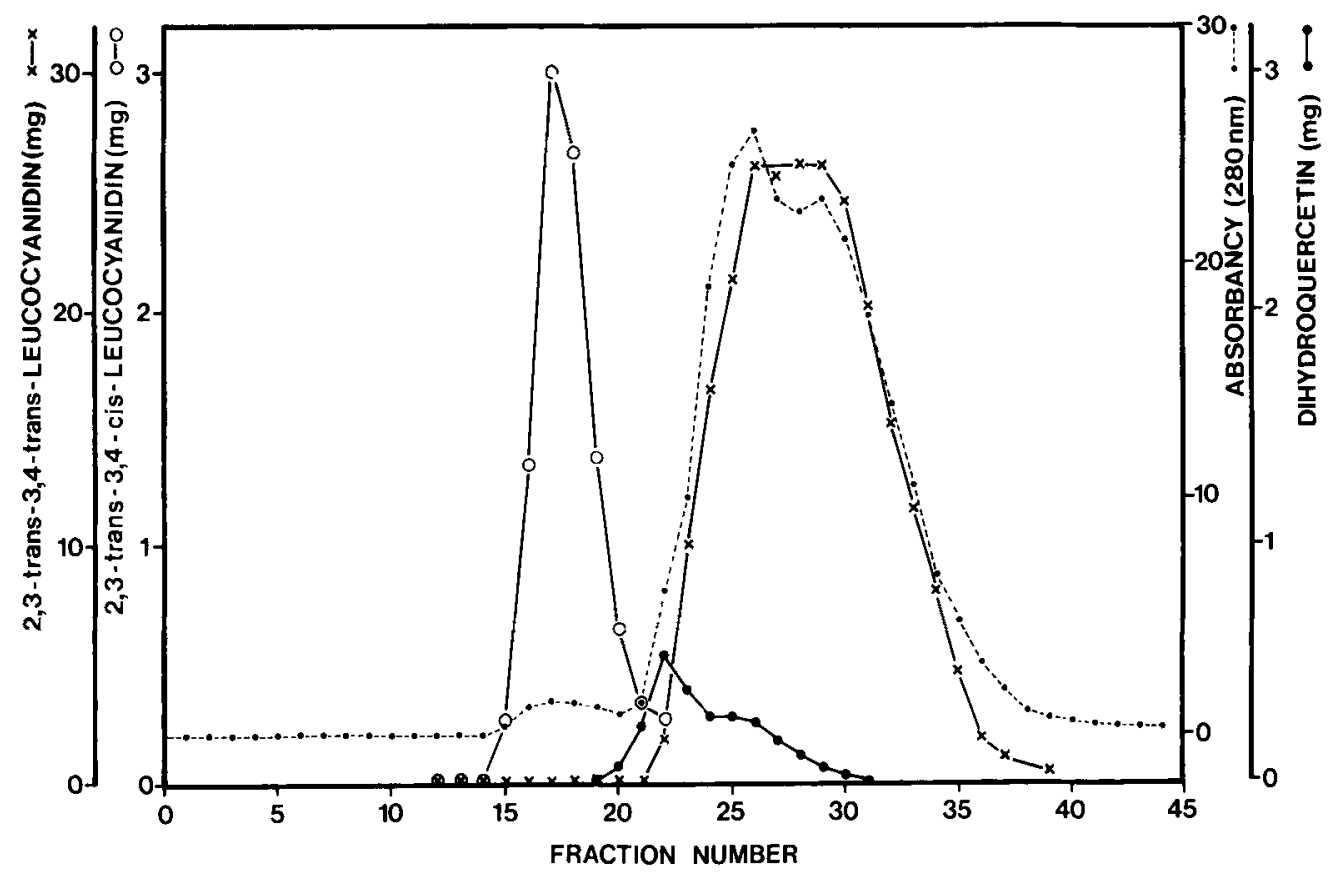

Figure 7. Elution profiles of 2,3-trans-3,4-trans-leucocyanidin, 2,3-trans-3,4-cis-leucocyanidin and dihydroquercetin which have been separated by a Sephadex LH-20 column $(2.5 \times 35 \mathrm{~cm})$ eluted with ethanol. The flowrate was $16 \mathrm{ml} \cdot \mathrm{h}^{-1}$ and $16 \mathrm{ml}$ fractions were collected. An aliqout of each fraction was analysed by HPLC using system IV (section 2.3.1) to determine the concentrations of the flavonoids.

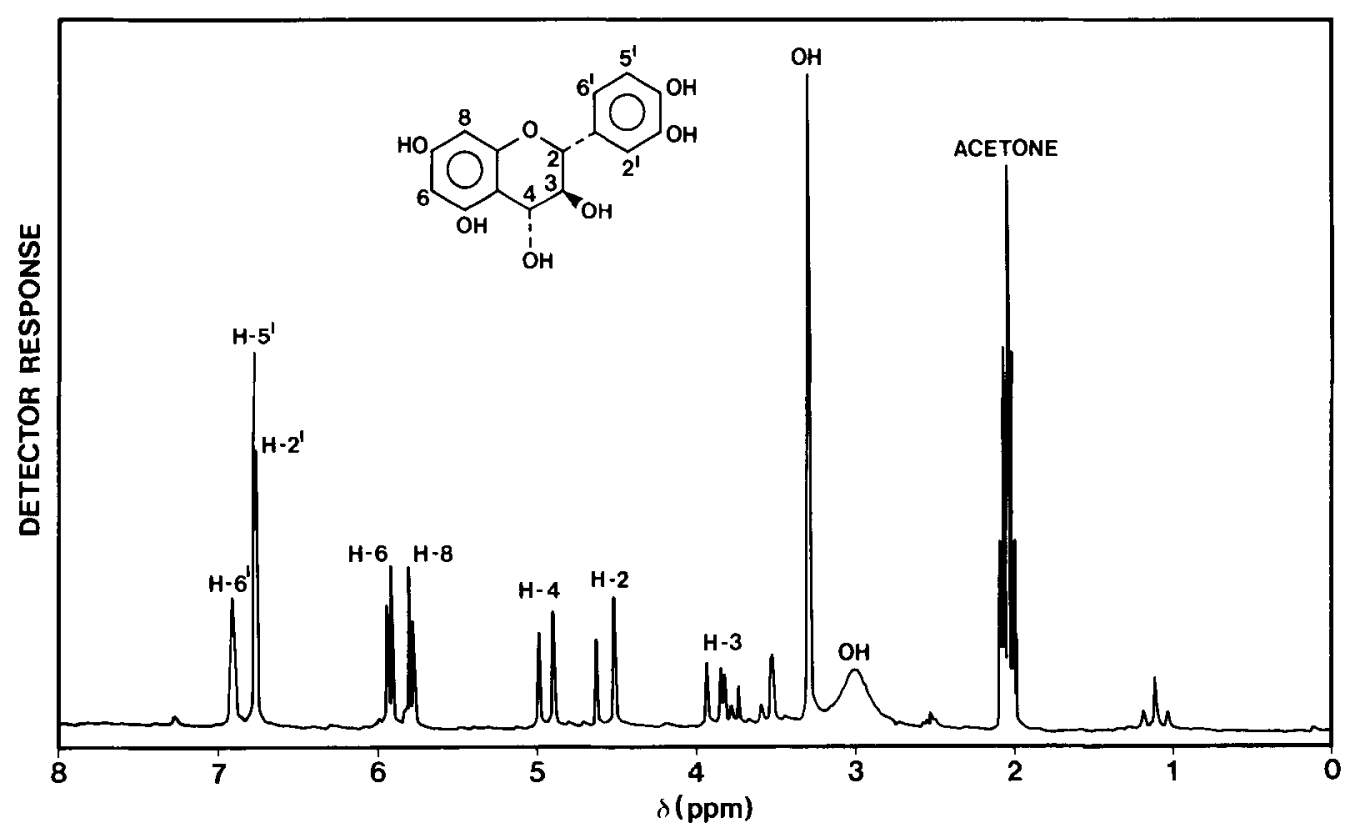

Figure 8. 90-MHz 'H NMR spectrum of (2R,3S,4R)-3,4,5,7,3',4'-hexahydroxyflavan (2,3-trans-3,4-trans-leucocyanidin) in $\mathrm{d}_{h}$-acetone at $20^{\circ} \mathrm{C}$. Acetone was used as internal standard. 


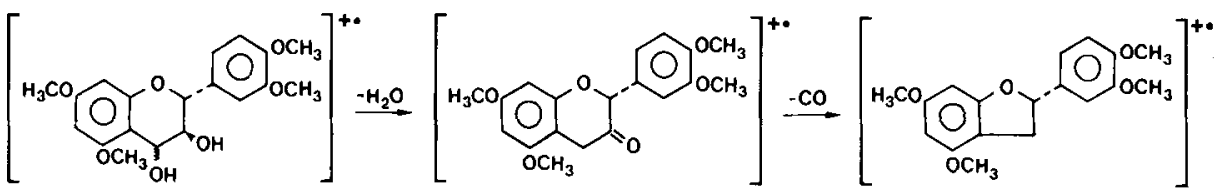

$M^{+*}, \quad \mathrm{~m} / \mathrm{z} 362(5 \%, 6 \%)$

$\mathrm{m} / 2344(20 \%, 6 \%)$

$\mathrm{m} / \mathrm{z} 316(53 \%, 15 \%)$

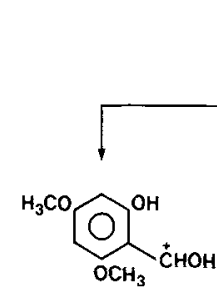

$m / 2183(17 \%, 27 \%)$<smiles>COc1ccc(/C=C/C=C(C)C(=O)O)cc1OC</smiles>

$\mathrm{m} / \mathrm{z} 180(77 \%, 100 \%)$ $\mathrm{m} / \mathrm{z} 165(15 \%, 22 \%)$ $-\mathrm{CH}_{3} \cdot$<smiles>C=C1C=CC(=O)C(CC(C)C=O)C1OC</smiles>

$\mathrm{m} / 2151(20 \%, 39 \%)$

Figure 9. Origin of the important mass ion fragments of (2R,3S,4R and S)-5,7,3',4'-tetramethoxyflavan-3,4-diol. The relative intensities obtained are given in parentheses (that for the 3,4-trans-diol to the left, and that for the 3,4-cis-diol to the right). $\mathrm{RDA}=$ retro Diels-Alder. Modified from ref. 7 ,

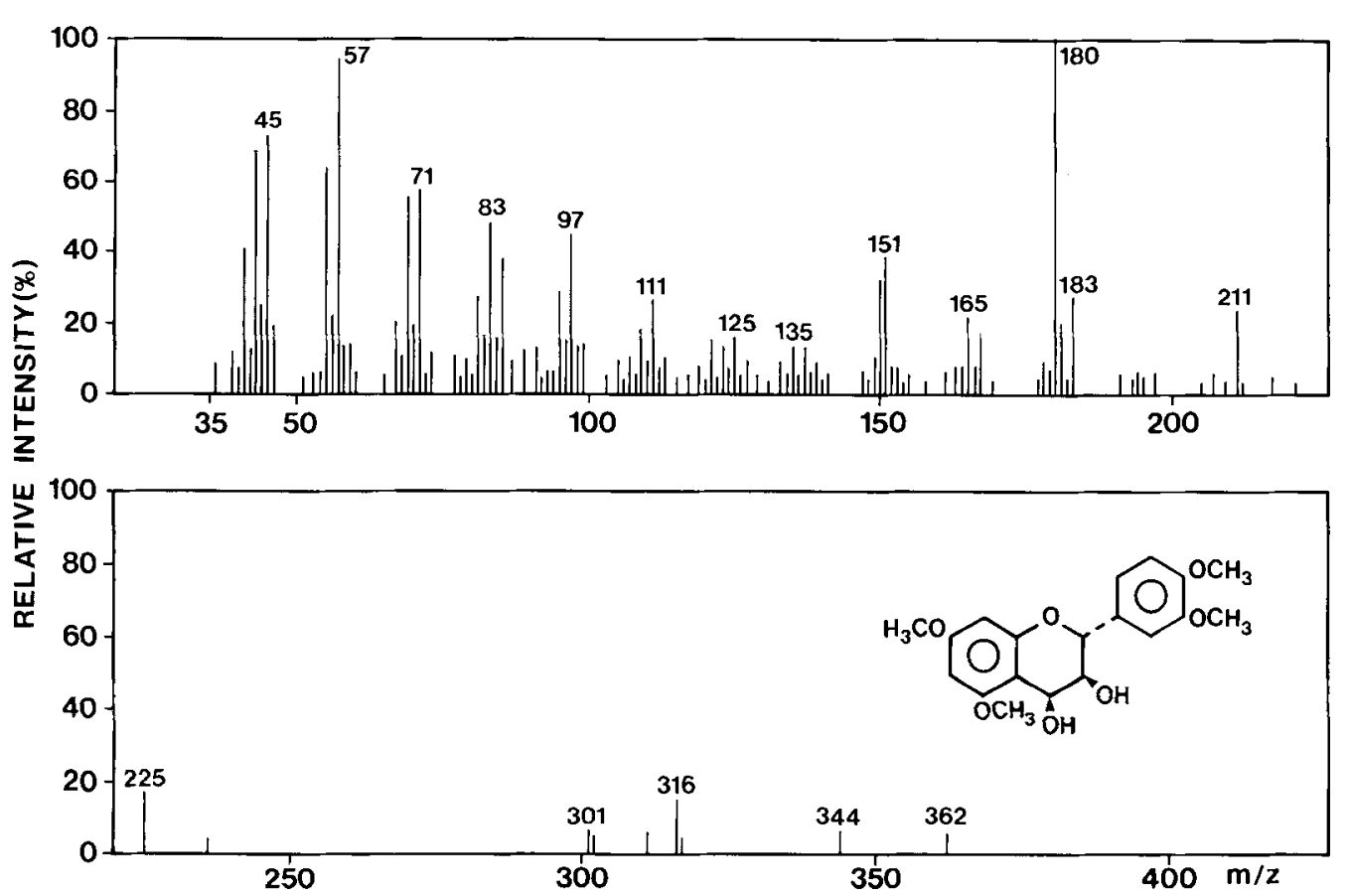

Figure 10. Mass spectrum of the tetramethyl ether of the minor leucocyanidin isomer ((2R,3S,4S)-5,7,3',4'-tetramethoxyflavan-3,4-diol). 


\subsection{Synthesis and characterization of two iso- meric leucocyanidins}

Leucocyanidin (a flavan-3,4-diol) is a suspected intermediate in the biosynthesis of catechin and procyanidins $(4,22,23,26,37,41)$. Two isomeric leucocyanidins (the 3,4-trans and 3,4-cis isomers) were therefore synthesized chemically to allow determination of their chromatographic properties. This information would enable the detection and identification of a radioactively labelled leucocyanidin isomer if synthesized by barley seeds fed $\left({ }^{14} \mathrm{C}\right)$-dihydroquercetin.

The two isomeric leucocyanidins formed by reduction of (+)-dihydroquercetin with $\mathrm{NaBH}_{4}$ were separated by column chromatography (Figure 7). The yields of the major and minor isomer were $50.0 \%$ and $2.3 \%$, respectively. Only $0.5 \%$ of the starting dihydroquercetin was recovered as such. The rest was probably converted to self-condensation products of the leucocyanidins.

The major isomer was conclusively identified as $(2 \mathrm{R}, 3 \mathrm{~S}, 4 \mathrm{R})-3,4,5,7,3^{\prime}, 4^{\prime}$ '-hexahydroxyflavan (3,4-trans-diol) by ' $H$ NMR and MS. The ' $H$ NMR spectrum (Figure 8 ) showed the following characteristic chemical shifts: $\delta 3.83(\mathrm{~m}, \mathrm{H}-3)$, 4.58 (d, J=10.0 Hz, H-2), 4.94 (d, J=7.8 Hz, $\mathrm{H}-4$ ), 5.80 (d, J=2.3 Hz, H-8), 5.93 (d, J=2.3 Hz, H-6), 6.77 (s, H-2'), 6.78 (s, H-5'), 6.91 (s, H-6'). This spectrum is identical to that obtained by PORTER and FOO (36), including the typical large coupling constants $\left(\mathrm{J}_{2.3}=10.0 \mathrm{~Hz}, \mathrm{~J}_{3.4}=7.8\right.$ $\mathrm{Hz}$ ) associated with the 2,3-trans-3,4-trans stereochemistry (2). The mass spectrum of the $5,7,3^{\prime}, 4^{\prime}$-tetramethyl ether showed the expected fragmentation pattern $(7,36)$. The important fragments and their relative intensities are given in Figure 9. A relatively small molecular ion peak $\left(\mathrm{M}^{+}\right)$is seen. The most prominent peak at $\mathrm{m} / \mathrm{z} 180$ arises from a retro Diels-Alder fission of the heterocyclic ring.

The minor isomer was also identified as a leucocyanidin by MS of the tetramethyl ether (Figures 9 and 10). Since the 2,3-trans stereochemistry of (+)-dihydroquercetin is maintained during the reduction of dihydroquercetin with $\mathrm{NaBH}_{4}$ (4), the minor leucocyanidin is probably $(2 \mathrm{R}, 3 \mathrm{~S}, 4 \mathrm{~S})-3,4,5,7,3^{\prime}, 4^{\prime}$ '-hexahydroxyflavan (3,4-cis-diol). The $R_{f}$ value $(0.22)$ ob- tained for the tetramethyl ether of the minor isomer by TLC on a kieselgel plate developed in benzene:acetone $(4: 1, v / v)$ is in agreement with that reported by PORTER and FOO (36) for $(2 \mathrm{R}, 3 \mathrm{~S}, 4 \mathrm{~S})-5,7,3^{\prime}, 4^{\prime}$-tetramethoxyflavan3,4-diol $\left(\mathbf{R}_{f}, 0.24\right)$. The latter was synthesized by reduction of dihydroquercetin tetramethyl ether with $\mathrm{NaBH}_{4}$. Furthermore, the minor leucocyanidin isomer condensed in acid with added $\left({ }^{14} \mathrm{C}\right)$-catechin to form the expected alltrans dimer and trimer of catechin (Figure 11). $55 \%$ of the diol was recovered in procyanidin $\mathrm{B} 3$ and $17 \%$ in procyanidin $\mathrm{C} 2$.

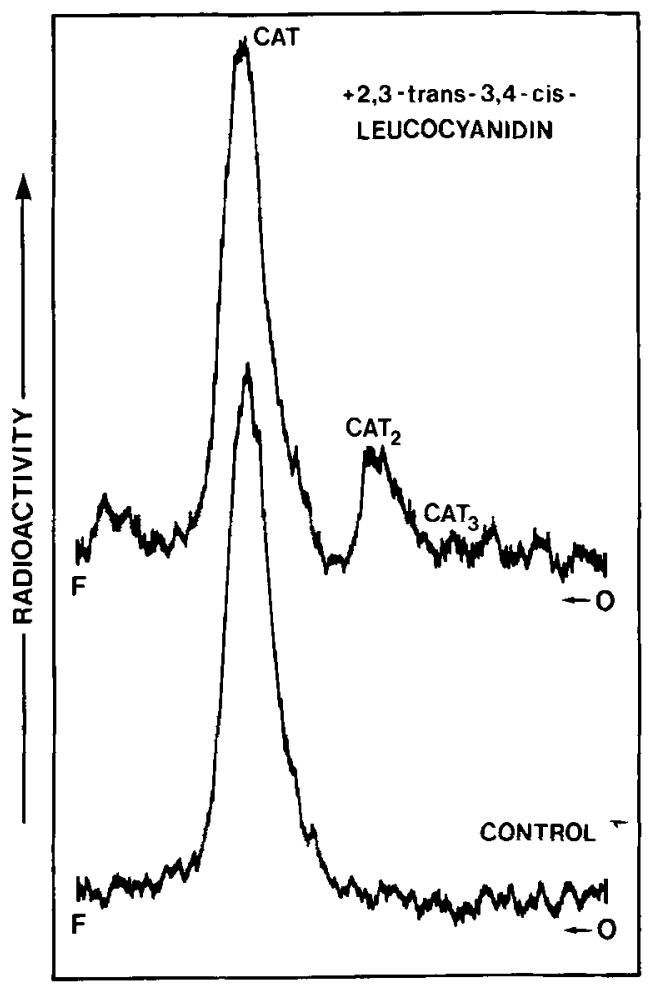

Figure 11. Radio-thin layer chromatograms of products formed by addition of the minor leucocyanidin isomer (2,3-trans-3,4-cis-leucocyanidin) to an acidic solution of $\left({ }^{14} \mathrm{C}\right.$ )-catechin (upper) and a control where leucocyanidin was omitted (lower). Strong vanillin positive bands corresponding to procyanidins $\mathrm{B} 3$ and $C 2$ were seen when spraying a narrow vertical strip of the upper plate with the vanillin reagent. Separation was carried out using TLC plates, developed in SBAWC (section 2.3.2). $\mathrm{CAT}=$ catechin, $\mathrm{CAT}_{2}=$ procyanidin $\mathrm{B} 3, \mathrm{CAT}_{3}=$ procyanidin $\mathrm{C} 2, \mathrm{O}=$ origin, $\mathrm{F}=$ solvent front. 
Table II.

Incorporation of $1 \mu \mathrm{Ci}\left({ }^{14} \mathrm{C}\right)$-dihydroquercetin into catechin and procyanidin $\mathrm{B3}$ by various tissue preparations of wild type barley seeds (cpm).

\begin{tabular}{lcc}
\hline Plant tissue $^{a}$ & Catechin & Procyanidin B3 \\
\hline Excised spike & 0 & 0 \\
25 seeds minus awns & 9,900 & 2,100 \\
25 seeds minus awns and husks & 12,300 & 3,200 \\
25 seeds minus awns, endosperms and aleurone layers & 41,800 & 9,900 \\
25 seeds minus awns, husks, endosperms and aleurone layers & 78,700 & 11,800 \\
\hline
\end{tabular}

${ }^{a}$ Incubation procedure for the excised spike is described in section 3.5.1, and for the other preparations in section 2.8 .

Each of the flavan-3,4-diols synthesized showed the characteristics of leucocyanidins $(8$, 21 ), i.e., conversion to cyanidin upon hydrolysis in acid, a positive reaction with the vanillin reagent (section 2.10) and a $R_{f}$ value similar to that of catechin in the BAW solvent system. The chromatographic properties of the 3,4-diols are given in Table 1 . That the 3,4-cis-diol is more water soluble than the 3,4-trans-diol is shown by the lower $R_{f}$ values in three of the five TLC systems used and by the smaller elution volume on the reverse phase HPLC column.

The 3,4-trans-diol was highly unstable in acid and epimerized at C-4 to give the 3,4-cis-diol. When the 3,4-trans isomer was collected from the HPLC (system IV), left in the 5\% acetic acid eluate for 10 minutes and reinjected into the HPLC, a 1:1 ratio of 3,4-trans-diol and 3,4-cisdiol was obtained. The 3,4-cis diol did not give rise to other products when kept in the eluate for 10 minutes.

STAFFORD and LESTER (41) have also isolated two 2,3-irans-3,4-diol isomers after reduction of dihydroquercetin with $\mathrm{NaBH}_{4}$. The less water soluble isomer was the major product isolated as in the present study. The chromatographic properties and the stability to acid reported for these two isomers are very similar to those described in the present study for the 3,4-transdiol and 3,4-cis-diol. STAFFORD and LESTER obtained, for example, elution volumes of 13.0 and $22.5 \mathrm{ml}$, respectively, for the two diols using $\mathrm{a} \mathrm{C}_{18}$-Partisil ODS3 HPLC column eluted isocratically with $5 \%$ acetic acid. These values are comparable with the elution volumes of 13.05 and $21.60 \mathrm{ml}$ obtained for the 3,4-cis-diol and 3,4-trans-diol, respectively, using HPLC system IV (section 2.3.1). STAFFORD and LESTER, however, hypothesized that the more water soluble isomer was the 3,4-trans-diol and the less water soluble isomer the 3,4-cis-diol which is in contrast to the conclusions drawn here on the basis of ${ }^{1} \mathrm{H}$ NMR and MS.

\subsection{Incorporation of $\left({ }^{14} \mathrm{C}\right)$-dihydroquercetin into catechin and procyanidins in maturing barley seeds}

3.5.1. Incorporation of label by wild type seeds For the administration of $\left({ }^{14} \mathrm{C}\right)$-dihydroquercetin to barley seeds, spikes were harvested 12 days after flowering at which developmental stage the biosynthesis of catechin, procyanidin B3 and procyanidin C2 is in a linear phase in wild type seeds (Figure 2). Several techniques for administering $1 \mu \mathrm{Ci}\left({ }^{14} \mathrm{C}\right)$-dihydroquercetin were tested (Table II). No detectable incorporation of label into catechin and procyanidin B3 occurred in intact spikes. The latter had been cut off $1-2 \mathrm{~cm}$ below the lowermost glume, stood in $200 \mu \mathrm{l}$ aqueous solution of $\left({ }^{14} \mathrm{C}\right)$-dihydroquercetin and were left for 24 hours in the Weiss growth chamber under the conditions detailed in section 2.1. When 25 seeds from which the awns were cut off were incubated in an Erlenmeyer flask with $2 \mathrm{ml}$ aqueous precursor solution labelled catechin and procyanidin B3 were formed. A similar extent of incorporation was observed when both husks and awns were removed from the seeds. If, instead of removing the husks, the endosperm and adhering aleurone layers were squeezed out from awnless seeds, 
a 2-fold increase of $:$ label incorporated into catechin and procyanidin B3 resulted. Even more label was incorporated when the husk, in addition to awn, endosperm and aleurone layer, was removed from the seed and the remaining pericarp-testa tissue incubated.

Labelled dihydroquercetin was not detected in extracts of seeds devoid of the husk, but constituted the majority of label in extracts of seeds containing the husk. In the latter case the labelled dihydroquercetin present in the extracts was apparently not taken up by the pericarptesta tissue but stuck to the surface of the waxy husk. This may account for the higher incorporation of label into catechin and procyanidin B3 in seeds without husk compared to seeds with husk, since more substrate is available for synthesis when the husk is removed.

The marked increase in label incorporated into catechin and procyanidin B3 when removing the endosperm and the adhering aleurone layer from the seed indicates that the testa layer is the site of catechin and procyanidin biosynthesis. By removing the aleurone layer and endosperm, the testa becomes directly exposed to the incubation medium, facilitating the uptake of substrate by the tissue. Combining this observation with a recent report (1) that catechin and proanthocyanidins are concentrated in the testa of the mature seed leads to the conclusion that these compounds are synthesized and deposited in the same tissue.

The few cell layers constituting the testa were not isolable from the pericarp and therefore the combined pericarp-testa tissue was used in the feeding experiments. A radio-TLC scan of the ethyl acetate extractable products formed by wild type seeds incubated with $\left({ }^{14} \mathrm{C}\right)$-dihydroquercetin is shown in Figure $12 \mathrm{~A}$. Radioactively labelled catechin, procyanidin $\mathrm{B} 3$ and procyanidin $\mathrm{C} 2$ were synthesized, indicating that dihydroquercetin is an in vivo precursor of these compounds. The radioactive band at $R_{f} 0.95$ was not identified. It was a yellow compound that could be eluted from the cellulose plate with methanol. TLC in BAW, CAW and 15\% HOAc gave $R_{f}$ values of $0.94,0.82$ and 0.76 , respectively. Thus the unknown is not quercetin which is a potential product synthesized by the seeds when feeding $\left({ }^{14} \mathrm{C}\right)$-dihydroquercetin, but is believed to be a degradation product of $\left({ }^{14} \mathrm{C}\right)$ dihydroquercetin.

The flavonoids of interest were satisfactorily separated by HPLC using system IV (Table I, Figure $13 \mathrm{~B}$ ), except procyanidin $\mathrm{C} 2$, which eluted almost simultaneously with 3,4-transdiol. Subjecting the extract to HPLC analysis revealed several minor radioactive peaks in addition to the major peaks corresponding to catechin and procyanidin B3 (Figure $13 \mathrm{~A}$ ). The

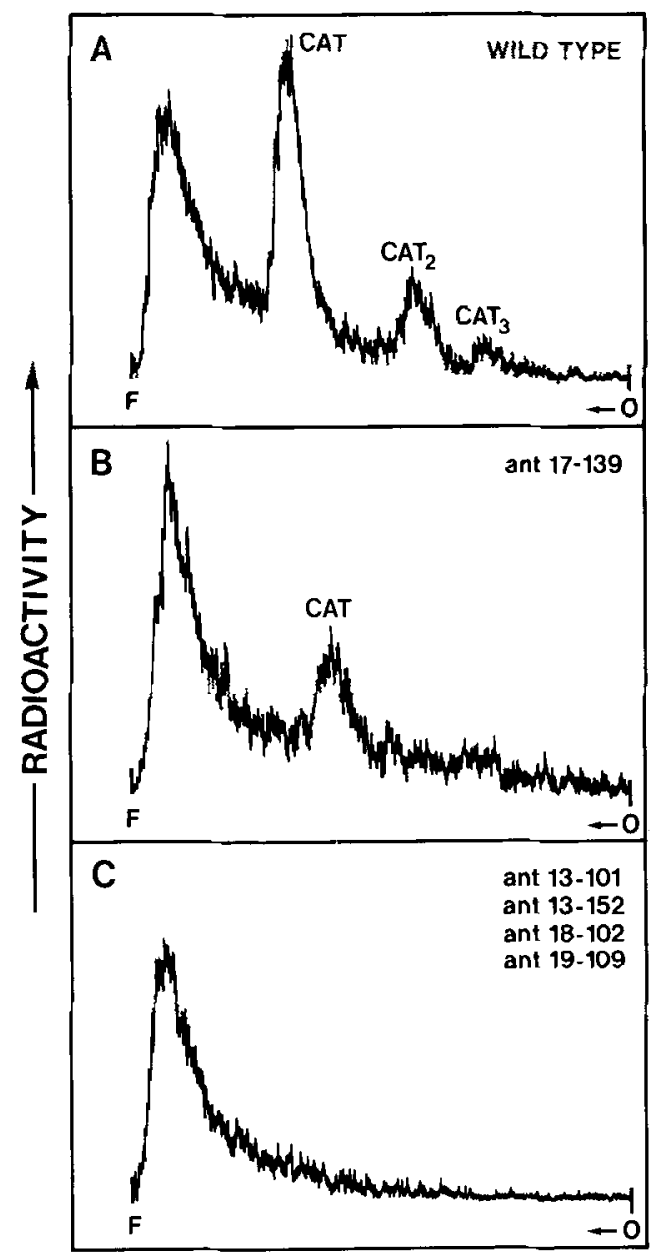

Figure 12. Radio-thin layer chromatograms of ethyl acetate soluble products formed by feeding $\left({ }^{i 4} \mathrm{C}\right)$-dihydroquercetin to pericarp-testa tissue of (A) wild type, (B) ant 17-139, and (C) ant 13-101, ant 13-152, ant 18-102 and ant 19-109. From 21,900 to $62,400 \mathrm{cpm}$ were applied to each plate which was developed using sBAWC (section 2.3.2). CAT $=$ catechin. $\mathrm{CAT},=$ procyanidin $\mathrm{B} 3, \mathrm{CAT}_{3}=$ procyanidin $\mathrm{C} 2, \mathrm{O}=$ origin, $\mathrm{F}=$ solvent front. 


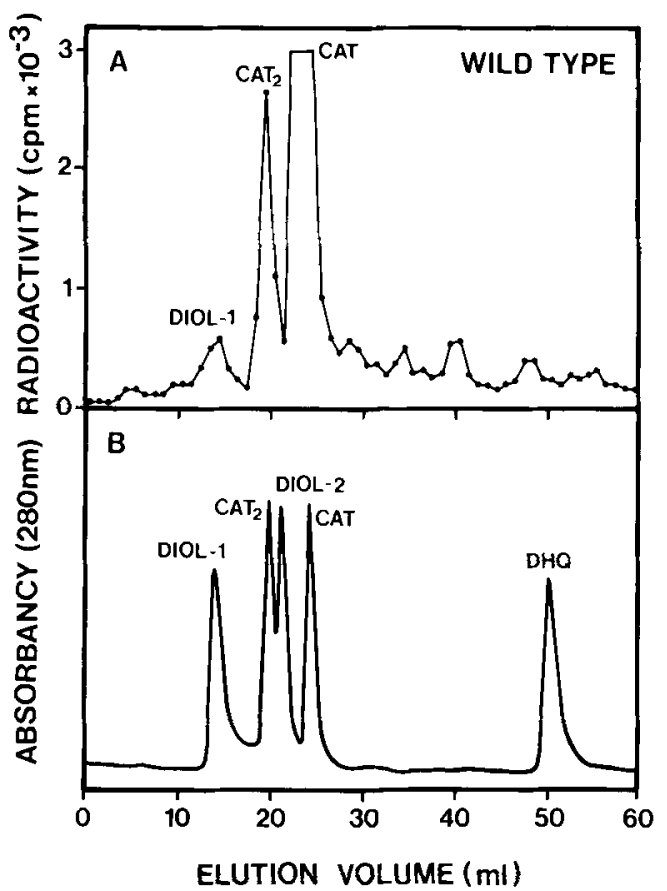

Figure 13. High pressure liquid chromatograms of (A) ethyl acetate soluble products formed by feeding $\left({ }^{14} \mathrm{C}\right)$ dihydroquercetin to pericarp-testa tissue of wild type ( $25 \mu 1$, corresponding to pericarp-testa tissue from 6.25 seeds, was injected), and (B) a mixture of flavonoid standards. Separations were carried out using HPLC system IV (section 2.3.1). DIOL-1 = 2,3-trans-3,4-cis leucocyanidin, $\mathrm{CAT}_{2}=$ procyanidin $\mathrm{B} 3, \mathrm{DIOL}-2=$ 2,3-trans-3,4-trans-leucocyanidin, $\mathrm{CAT}=$ catechin, $\mathrm{DHQ}=$ dihydroquercetin. compound migrating near the front on the TLC plate was not eluted from the HPLC column with the acetic acid system used. Virtually no labelled dihydroquercetin aglucone was recovered in the plant extract. Probably the substrate, taken up by the pericarp-testa tissue, is immediately glucosilated and thus not detected, since only ethyl acetate soluble products were analysed.

No radioactive peak corresponding to 3,4trans-diol was detected. Formation of the labelled 3,4-cis-diol from $\left({ }^{14} \mathrm{C}\right)$-dihydroquercetin indicates that the leucocyanidin with the 3,4-cis stereochemistry is an intermediate in catechin and procyanidin biosynthesis. The other minor labelled peaks seen in Figure $13 \mathrm{~A}$ were not identified. No label was incorporated into dihydromyricetin and prodelphinidins, i.e., flavonoids having a 3',4',5'-hydroxylation pattern.

The amounts of label incorporated into catechin and procyanidins are shown in Table III. $4.7 \%$ of the radioactivity fed was recovered in these flavonoids. Using the rates of synthesis given in section 3.1 , the expected ratio can be calculated among label incorporated into catechin, procyanidin $\mathrm{B} 3$ and procyanidin $\mathrm{C} 2$ as 10:0.9:0.5, assuming that just one catechin unit in the procyanidin molecules is labelled. The observed ratio was $10: 1.5: 0.44$, revealing that $67 \%$ more label than expected was incorporated into procyanidin $\mathrm{B} 3$. This effect was also obser-

Table III.

Synthesis of catechin and procyanidins by pericarp-testa tissue prepared from 25 seeds of wild type barley and proanthocyanidin free mutants fed $1 \mu \mathrm{Ci}\left({ }^{14} \mathrm{C}\right)$-dihydroquercetin.

\begin{tabular}{|c|c|c|c|c|c|c|c|c|c|}
\hline \multirow{2}{*}{ Genotype } & \multicolumn{2}{|c|}{ Catechin } & \multicolumn{2}{|c|}{ Procyanidin B3 } & \multicolumn{2}{|c|}{ Procyanidin $\mathrm{C} 2$} & \multicolumn{2}{|c|}{ 3,4-cis-diol } & \multirow{2}{*}{$\begin{array}{l}\text { 3,4-trans- } \\
\text { diol } \\
\mathrm{cpm}\end{array}$} \\
\hline & cpm & $\mathrm{nmol}$ & $\mathrm{cpm}$ & $\mathrm{nmol}$ & $\mathrm{cpm}$ & $\mathrm{nmol}$ & $\mathrm{cpm}$ & $\mathrm{nmol}$ & \\
\hline Wild type & 78,700 & 14.3 & 11,800 & $2.15^{\mathrm{a}}$ & 3,500 & $0.64^{\mathrm{a}}$ & 6,000 & 1.09 & - \\
\hline ant $17-139$ & 16,500 & 3.00 & 4,400 & $0.40^{\mathrm{b}}$ & - & - & - & - & - \\
\hline ant $18-102$ & 1,900 & 0.35 & 500 & $0.05^{b}$ & - & - & - & - & - \\
\hline ant $19-109$ & 1,700 & 0.31 & 2,600 & $0.24^{b}$ & - & - & - & - & - \\
\hline ant $13-101$ & - & - & - & - & - & - & - & - & - \\
\hline ant $13-152$ & - & - & - & - & - & - & - & - & - \\
\hline
\end{tabular}

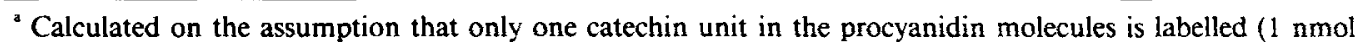

$=5,500 \mathrm{cpm}$ ).

${ }^{\mathrm{b}}$ Calculated on the assumption that both catechin units are labelled $(1 \mathrm{nmol}=11,000 \mathrm{cpm})$.

- = less than $100 \mathrm{cpm}$ or $0.02 \mathrm{nmol}$. 


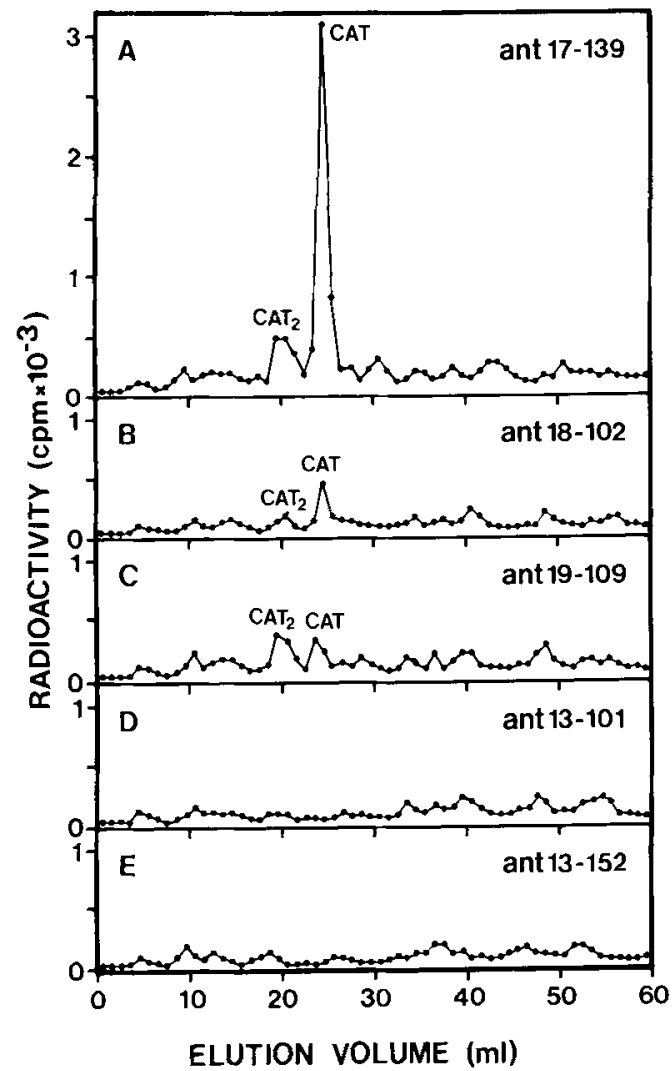

Figure 14. High pressure liquid chromatograms of ethyl acetate soluble products formed by feeding $\left({ }^{14} \mathrm{C}\right)$ dihydroquercetin to pericarp-testa tissue of (A) ant 17-139,(B) ant 18-102, (C) ant 19-109, (D) ant 13-101, and (E) ant 13-152. See footnote for Figure 13.

ved in the incorporation experiments in Table II, to an even higher extent. Control experiments showed that this effect is not due to a spontaneous condensation during the purification procedure between labelled catechin formed by the seeds and the added leucocyanidin carrier, since the effect was also observed when no leucocyanidin was added. A selective stimulation of the procyanidin B3 synthesis, however, may be occurring in vitro but not in vivo.

\subsubsection{Incorporation of label by seeds of proanthocyanidin free mutants}

The results of feeding $\left({ }^{14} \mathrm{C}\right)$-dihydroquercetin to pericarp-testa tissue prepared from proanthocyanidin free mutants belonging to different loci are presented in Figures $12 \mathrm{~B}, \mathrm{C}$, and 14 plus Table III. The mutant ant 17-139 was capable of synthesizing catechin and procyanidin B3 from dihydroquercetin at a rate of synthesis approximately $20 \%$ of that for wild type. The ratio between $\mathrm{nmol}$ of catechin and procyanidin B3 formed by ant 17-139 is 7.5:1, assuming that the specific activity of procyanidin $B 3$ is twice that of catechin and recalling that no pool of unlabelled catechin exists in this proanthocyanidin free mutant. This ratio is in good agreement with that of $6.8: 1$ obtained for wild type. The mutants ant 18-102 and ant 19-109 synthesized such small amounts of catechin and procyanidin B3 that they were not detectable by the radioTLC analysis (Figure $12 \mathrm{C}$ ) but only by HPLC analysis (Figure 14B, C). The rates of catechin and procyanidin B3 synthesis observed for ant $18-102$ were $2.4 \%$ and $2.1 \%$, respectively, of those for wild type. The corresponding figures for ant $19-109$ were $2.2 \%$ and $11 \%$, respectively. Two mutants in the gene ant 13 were tested, and both were totally inactive with respect to catechin and procyanidin synthesis.

\section{DISCUSSION}

\subsection{Biosynthetic pathway for the conversion of dihydroquercetin into catechin and procyanidins}

A biosynthetic pathway for the conversion of dihydroquercetin into catechin and procyanidins based on the above results is shown in Figure 15.

That dihydroquercetin is a precursor of catechin and procyanidins, as proposed earlier (18, $22,23,26,37,39$ ), was established by feeding $\left({ }^{14} \mathrm{C}\right)$-dihydroquercetin to pericarp-testa tissue prepared from wild type and recovering the label in the appropriate products. As an alternative to a pathway via dihydroquercetin, HASLAM suggested a pathway via 2 -hydroxychalcone (22, $23,26)$. This hypothesis is no longer tenable. The simultaneous synthesis of radioactively labelled 2,3-trans-3,4-cis-leucocyanidin, catechin, procyanidin $\mathrm{B} 3$ and procyanidin $\mathrm{C} 2$ observed when feeding $\left({ }^{14} \mathrm{C}\right)$-dihydroquercetin to wild type barley seeds strongly suggests that the 3,4cis-diol is an intermediate in catechin and procyanidin synthesis. This is in agreement with 


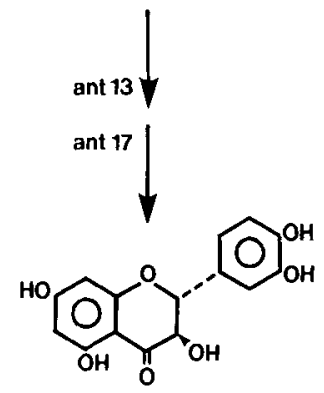

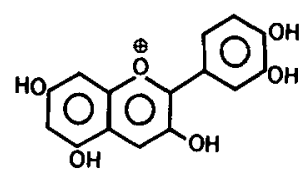

CYANIDIN (ANTHOCYANIDIN) ant 1 to ant 12 ant 14 to ant 16 DIHYDROQUERCETIN

2,3-trans-3,4-cis-LEUCOCYANIDIN

CATECHIN

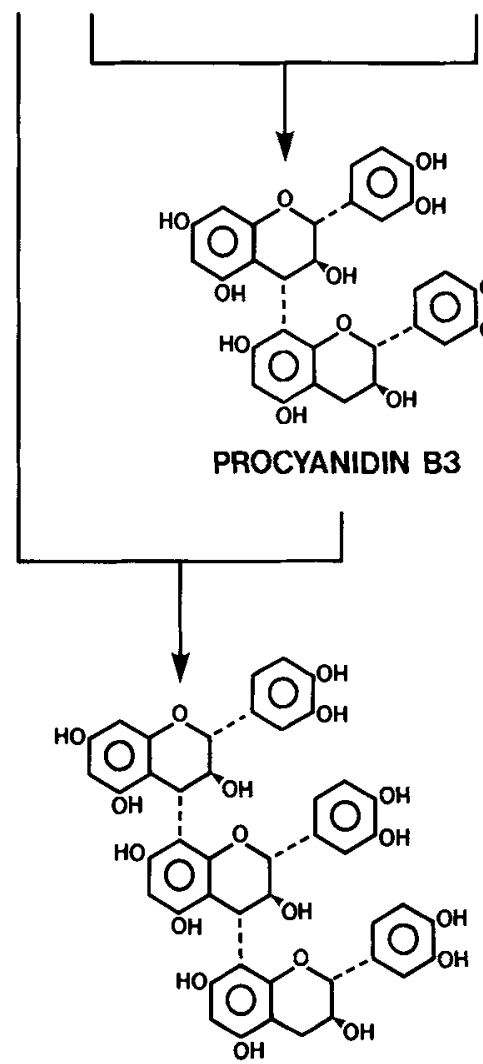

PROCYANIDIN C2

Figure 15. Proposed biosynthetic pathway leading from dihydroquercetin to catechin, procyanidins and cyanidin showing the likely sites of action of 19 ant genes. 


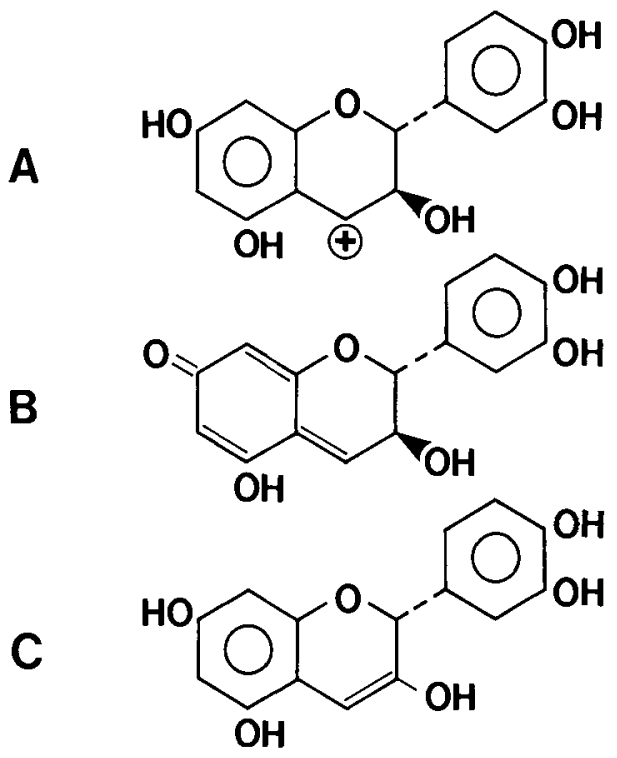

Figure 16. Structures of postulated intermediates in catechin and procyanidin biosynthesis. (A) Flavanyl4-carbocation, (B) quinone methide, and (C) flav-3-en3-ol.

the idea that a leucocyanidin is involved in the biosynthesis of these compounds $(4,22,23,26$, 37, 41). STAFFORD and LESTER (41) have demonstrated a NADPH-dependent reductase activity, capable of converting dihydroquercetin to a flavan-3,4-diol, in crude soluble protein extracts from cell suspension cultures of Douglas fir. The enzymatically produced 3,4-diol was deduced to be the 2,3-trans-3,4-trans isomer when it produced cyanidin upon acid hydrolysis and it condensed nonenzymatically with catechin in acidic solution to form procyanidin B3 $(37,41)$. These two criteria, however, can not be used to distinguish the 3,4-trans-diol from the 3,4-cis-diol, since the same reactions are expected for the 3,4-cis-diol. The 3,4-diol formed by the protein extracts of Douglas fir was similar to the minor more"water soluble of the two isomers formed by reduction of dihydroquercetin with $\mathrm{NaBH}_{4}$. In the present study the more water soluble isomer was demonstrated to be the 2,3-trans-3,4-cis isomer. Thus, both cell suspension cultures of Douglas fir and pericarp-testa tissue of barley most likely synthesize the 2,3-trans-3,4-cis isomer of leucocyani- din. (Preliminary experiments using crude protein extracts prepared from pericarp-testa tissue of wild type barley revealed a NADPH-dependent reduction of dihydroquercetin to the 3,4 cis-diol).

It has been postulated that oligomeric procyanidins in general are synthesized by the addition of a stereospecific flavanyl-4-carbocation (Figure $16 \mathrm{~A}$ ) to a flavan-3-ol (catechin or epicatechin) or to an already existing procyanidin chain $(4,22,23,26,37)$. Support for a condensation of units from separate metabolic pools came from tracer experiments $(26,40)$, showing that more label was incorporated into the upper unit of a procyanidin dimer than into the lower unit. The status of flavanyl-4-carbocation as an intermediate in the procyanidin biosynthesis is due, however, solely to in vitro reactions. The in vitro reduction product of dihydroquercetin, mainly 2,3-trans-3,4-trans-leucocyanidin, is easily condensed with catechin in acid to give all-trans procyanidins $(4,8,9,11,25,41)$. Since the stereochemistry at C-4 is preserved, the in vitro condensation must proceed through a $S_{N} 1$ mechanism, i.e., through the flavanyl-4-carbocation, as inferred for the in vivo synthesis. HEMINGWAY and FoO (25), however, found that the base-catalyzed condensation of 2,3trans-3,4-trans-leucocyanidin with catechin through a quinone methide (Figure $16 \mathrm{~B}$ ) proceeded more rapidly than the acid-catalyzed through the flavanyl-4-carbocation. They concluded that the quinone methide is more likely to be involved in the biosynthesis of procyanidins than the flavan-4-carbocation intermediate.

Whether the flavanyl-4-carbocation or the quinone methide is the actual electrophile condensing with catechin in vivo, the highly reactive electrophilic species most probably only exists at the transition state in the active site of an enzyme. That the enzymatic reduction of dihydroquercetin results in the 3,4-cis-diol permits one to suggest a third mechanism for the in vivo condensation, namely through an $\mathrm{S}_{\mathrm{N}} 2$ reaction between the 3,4-cis-diol and catechin not involving one of the highly reactive electrophilic species. The inversion of configuration at C-4 associated with this $\mathrm{S}_{\mathrm{N}} 2$ mechanism results in formation of the all-trans procyanidin dimer 
(Figure 15). Thus whatever the mechanism of enzyme catalysis, the 3,4-cis-diol can be condensed with catechin to give procyanidin B3 in one enzymatic step.

In the speculative pathway for catechin and proanthocyanidin biosynthesis proposed by Haslam $(22,23,26)$, the reduction of dihydroquercetin to a leucocyanidin was followed by a dehydration of leucocyanidin to give a flav-3en-3-ol (Figure 16 C). This was thought to be the key intermediate that by protonation gave rise to the postulated flavanyl-4-carbocation. In the biosynthetic pathway presented in Figure 15, the flav-3-en-3-ol intermediate is omitted (37) and the 3,4-cis-diol is believed to be the key intermediate. HASLAM further suggested that procyanidins are synthesized when the supply of biological reductant is rate-limiting so that the postulated flavanyl-4-carbocation might escape from the active site of a reductase and react with an already formed reduced product (catechin or epicatechin) to produce dimers, trimers etc. This hypothesis seems unlikely, since the synthesis of catechin, procyanidin B3 and procyanidin $\mathrm{C} 2$ occurred simultaneously in barley 8-16 days after flowering (Figure 2) when chlorophyll is still present and biological reductant will probably not be rate-limiting. More likely specific enzymes are involved in the biosynthesis of catechin and procyanidins.

Thus, I propose that at least four enzymes are involved in the conversion of dihydroquercetin to catechin and procyanidins: (i) a reductase, converting dihydroquercetin to its 3,4-cis-diol, (ii) a second reductase, converting 3,4-cis-diol to catechin, (iii) a condensing enzyme, adding 3,4-cis-diol to catechin to form the all-trans dimeric procyanidin, (iv) a second condensing enzyme, adding 3,4-cis-diol to the procyanidin dimer to form the all-trans trimer.

\subsection{Site of action of ant genes}

The most likely sites of action of ant 13, ant 17 , ant 18 and ant 19 in the biosynthetic pathway to catechin and procyanidins are indicated in Figure 15, together with the sites of the other ant genes (ant 1-ant 12, ant 14-ant 16) known to participate in anthocyanin but not proanthocyanidin biosynthesis $(27,28)$.
The gene ant 18 appears to control the reduction of dihydroquercetin, since this intermediate accumulated in seeds of ant 18-102. The capability of ant 18-102 seeds to synthesize small amounts of catechin and procyanidin B3 when fed $\left({ }^{14} \mathrm{C}\right)$-dihydroquercetin is probably due to an incomplete genetic block. The gene ant 19 is believed to function in the postulated reduction of 2,3-trans-3,4-cis-leucocyanidin to catechin, since seeds of ant 19-109 are proanthocyanidin free but capable of synthesizing anthocyanins (28). This mutant is also considered slightly leaky due to a minor synthesis of catechin and procyanidin B3 from $\left({ }^{14} \mathrm{C}\right)$-dihydroquercetin. No labelled 3,4-cis-diol accumulated during the feeding experiments as might be expected. This result can not be attributed to a further conversion of the 3,4-cis-diol to anthocyanins, because the latter are synthesized in the husk (27) and not in the pericarp-testa tissue used for the feeding experiments. On the other hand a regulatory mechanism (a feedback inhibition) may prevent an extensive accumulation of the 3,4-cis-diol by inhibiting the reduction of dihydroquercetin when the 3,4-cis-diol is not metabolized further to catechin and procyanidins.

The leucocyanidin (Figure 15) rather than dihydroquercetin apparently serves as the last common intermediate in the synthesis of anthocyanins and proanthocyanidins, since seeds of ant 18-102, though accumulating dihydroquercetin, are not capable of synthesizing anthocyanins (28) in contrast to seeds of ant 19-109. The genes ant 1 to ant 12 and ant 14 to ant 16 must therefore control steps between 3,4-cisdiol and anthocyanins.

The gene ant 17 determines a step prior to dihydroquercetin, since ant 17-139, deficient in both proanthocyanidins and anthocyanins (28), was capable of converting $\left({ }^{14} \mathrm{C}\right)$-dihydroquercetin into catechin and procyanidin. Similarly, the gene ant 13 functions prior to dihydroquercetin, since mutants in this gene lack proanthocyanidin and anthocyanin (28) as well as dihydroquercetin. Unexpectedly, however, seeds of ant 13-101 and ant 13-152 unlike those of ant 17-139 were not capable of synthesizing catechin and procyanidins from $\left({ }^{14} \mathrm{C}\right)$-dihydroquercetin. Why the enzymes needed for the 
conversion of dihydroquercetin into catechin and procyanidins are present in ant 17-139 but absent in the ant 13 mutants is not known. Assuming that ant 13 blocks a step earlier in the pathway than does ant 17 , it can be speculated that a given intermediate, responsible for induction of these enzymes, is synthesized in ant 17-139 but not in the ant 13 mutants.

In future work of isolating and characterizating the enzymes involved in the conversion of dihydroquercetin into catechin and procyanidin the barley mutants blocked after as well as before dihydroquercetin will provide helpful tools especially in regard to the biosynthesis of these enzymes.

\section{ACKNOWLEDGEMENTS}

Dr. P. VON WETTSTEIN-KNOWLES is thanked for helpful suggestions throughout this work and for reviewing the manuscript. Thanks are also due to Dr. A.W. SCHRAM for providing seeds of petunia mutant W78, to B. JENDE-STRID for helpful discussions, to H. OUTTRUP for providing proanthocyanidin standards, to Dr. J.Ø. MADSEN for taking the mass spectra, to Dr. M. BEGTRUP for taking the ${ }^{1} \mathrm{H}$ NMR spectrum, to N. RASMUSSEN for preparing the figures, and to B. PeTERSEN for growing the plants.

\section{REFERENCES}

1. Aastrup, S., H. Outtrup \& K. Erdal: Location of the proanthocyanidins in the barley grain. Carlsberg Res. Commun. 49, 105-109 (1984)

2. Baig, M.I., J.W. Clark-Lewis \& M.J. Thompson: Flavan derivatives XXVII. Synthesis of a new racemate of leucocyanidin tetramethyl ether $(2,3$ cis-3,4-trans-isomer): N.M.R. spectra of the four racemates of leucocyanidin tetramethyl ether (5,7,3',4'-tetramethoxyflavan-3,4-diol). Aust. J. Chem. 22, 2645-2650 (1969)

3. BARZ, W. \& W. Hosel: Metabolism of flavonoids. In: The Flavonoids. J.B. Harborne, T.J. Mabry \& H. Mabry, eds., Chapman \& Hall, London. pp. 916-969 (1975)

4. Botha, J.J., D. Ferreira \& D.G. Roux: Synthesis of condensed tannins. Part 4. A direct biomimetic approach to $(4,6)$ - and (4,8)-biflavanoids. J. Chem. Soc. Perkin Trans. 1, 1235-1245 (1981)
5. Brandon, M.J., L.Y. Foo, L.J. Porter \& P. MeREDITH: Proanthocyanidins of barley and sorghum: Composition as a function of maturity of barley ears. Phytochemistry 21, 2953-2957 (1982)

6. BRITSCH, L., W. Heller \& H. GrisebaCH: Conversion of flavanone to flavone, dihydroflavonol and flavonol with an enzyme system from cell cultures of parsley. Z. Naturforsch. 36c, 742-750 (1981)

7. Clark-Lewis, J.W:: Flavan derivatives XXV. Mass spectra of 3-hydroxyflavanones, flavan-3ols, and flavan-3,4-diols. Aust. J. Chem. 21, 30253054 (1968)

8. Creasy, L.L. \& T. Swain: Structure of condensed tannins. Nature 208, 151-153 (1965)

9. Delcour, J.A., D. Ferreira \& D.G. Roux: Synthesis of condensed tannins. Part 9. The condensation sequence of leucocyanidin with $(+)$-catechin and with the resultant procyanidins. J. Chem. Soc. Perkin Trans. I, 1711-1717 (1983)

10. EbEL, J. \& K. Hahlbrock: Biosynthesis. In: The Flavonoids: Advances in Research. J.B. Harborne \& T.J. Mabry, eds., Chapman \& Hall, London. pp. 641-679 (1982)

11. Fonknechten, G., M. Moll, D. Cagniant, G. KIRSCH \& J.F. MULLER: Synthesis and characterisation of dimers of catechin and epicatechin. J. Inst. Brew. 89, 424-431 (1983)

12. Forkmann, G., W. Heller \& H. Grisebach: Anthocyanin biosynthesis in flowers of Matthiola incana. Flavanone 3- and flavonoid 3'-hydroxylases. Z. Naturforsch. 35c, 691-695 (1980)

13. FritsCh, H. \& H. GrisebaCH: Biosynthesis of cyanidin in cell cultures of Haplopappus gracilis. Phytochemistry 14, 2437-2442 (1975)

14. Gerats, A.G.M., P.de Vlaming, M. Doodeman, B. AL \& A.W. SCHRAM: Genetic control of the conversion of dihydroflavonols into flavonols and anthocyanins in flowers of Petunia hybrida. Planta $155,364-368$ (1982)

15. Glennie. C.W.: Preharvest changes in polyphenols, peroxidase, and polyphenol oxidase in sorghum grain. J. Agric. Food Chem. 29, 33-36 (1981)

16. Glennie, C.W., W.Z. Kaluza \& P.J. vaN NieKERK: High-performance liquid chromatography of procyanidins in developing sorghum grain. $\mathbf{J}$. Agric. Food Chem. 29, 965-968 (1981)

17. Goldstein, J.L.\&T.SWAin: Changes in tannins in ripening fruits. Phytochemistry 2, 371-383 (1963)

18. Grisebach, H. \& W. Barz: Biochemie der Flavonoide. Naturwissenschaften 56, 538-544 (1969)

19. GuPTA, R.K. \& E. Haslam: Plant proanthocyanidins. Part 5. Sorghum polyphenols. J. Chem. Soc. Perkin Trans. I, 892-896 (1978)

20. HAHLBROCK. K. \& H. GRISEBACH: Biosynthesis of flavonoids. In: The Flavonoids. J.B. Harborne, 
T.J. Mabry \& H. Mabry, eds., Chapman \& Hall, London. pp. 866-915 (1975)

21. HASLAM, E.: Natural proanthocyanidins. In: The Flavonoids. J.B. Harborne, T.J. Mabry \& H. Mabry, eds., Chapman \& Hall, London. pp. 505-559 (1975)

22. HASLAM, E.: Symmetry and promiscuity in procyanidin biosynthesis. Phytochemistry 16, 16251640 (1977)

23. Haslam, E.: Proanthocyanidins. In: The Flavonoids: Advances in Research. J.B. Harborne \& T.J. Mabry, eds., Chapman \& Hall, London. pp. 417447 (1982)

24. Hemingway, R.W., L.Y. Foo \& L.J. Porter: Linkage isomerism in trimeric and polymeric 2,3-cis-procyanidins. J. Chem. Soc. Perkin Trans. I, 1209-1216 (1982)

25. Hemingway R.W. \& L.Y. Foo: Condensed tannins: Quinone methide intermediates in procyanidin synthesis. J. Chem. Soc. Chem. Commun., 1035-1036 (1983)

26. JacQues, D., C.T. Opie, L.J. Porter \& E. Haslam: Plant proanthocyanidins. Part 4. Biosynthesis of procyanidins and observations on the metabolism of cyanidin in plants. J. Chem. Soc. Perkin Trans. I, 1637-1643 (1977)

27. Jende-STrid, B.: Mutations affecting flavonoid synthesis in barley. Carlsberg Res. Commun. 43, 265-273 (1978)

28. JeNDE-STRID, B.: Characterization of mutants in barley affecting flavonoid synthesis. In: Barley Genetics IV. Proc. 4th Int. Barley Genet. Symp., pp. 631-634 (1981)

29. Jende-Strid, B. \& B.L. Møller: Analysis of proanthocyanidins in wild type and mutant barley (Hordeum vulgare L.). Carlsberg Res. Commun. 46, 53-64 (1981)

30. Karl, C., G. Muller \& P.A. Pedersen: Ein neues Catechinglykosid aus Polypodium vulgare. $\mathrm{Z}$. Naturforsch. 37c, 148-151 (1982)

31. KHO, K.F.F., G.J.H. BENNINK \& H. WIERING: Anthocyanin synthesis in a white flowering mutant of Petunia hybrida by a complementation technique. Planta 127, 271-279 (1975)

32. MARKHAM, K.R.: Techniques of flavonoid identification. Academic Press, London, (1982)

Accepted by: H. Klenow, E. Lund \& S. O. Andersen
33. OutTrup, H: Structure of prodelphinidins in barley. Eur. Brewery Conv., Congr. Proc. Copenhagen 1981, 323-333 (1981)

34. OUtTrup, H. \& K. SChaumburg: Structure elucidation of some proanthocyanidins in barley by ' $\mathrm{H}$ $270 \mathrm{MHz}$ NMR spectroscopy. Carlsberg Res. Commun. 46, 43-52 (1981)

35. PATSCHKe, L. \& H. Grisebach: 4, 2', 4', 6'-Tetrahydroxychalcon-2'-glucosid- $\left(\beta-{ }^{14} \mathrm{C}\right)$ als Vorstufe für Catechine im Tee. Z. Naturforsch. 20b, 399 (1965)

36. PORTER, L.J. \& L.Y. Foo: Leucocyanidin: Synthesis and properties of $(2 R, 3 S, 4 R)-(+)$ $3,4,5,7,3$ ',4'-hexahydroxyflavan. Phytochemistry 21, 2947-2952 (1982)

37. STAFFORD, H.A.: Enzymic regulation of procyanidin biosynthesis, lack of a flav-3-en-3-ol intermediate. Phytochemistry 22, 2643-2646 (1983)

38. Stafford, H.A. \& H.H. Lester: Procyanidins (condensed tannins) in green cell suspension cultures of Douglas fir compared with those in strawberry and avocado leaves by means of $\mathrm{C}_{18}$-reversedphase chromatography. Plant Physiol. 66, 1085$1090(1980)$

39. Stafford, H.A. \& H.H. Lester: Proanthocyanidins and potential precursors in needles of Douglas fir and in cell suspension cultures derived from seedling shoot tissues. Plant Physiol. 68, 10351040 (1981)

40. StafFord, H.A., M. Shimamoto \& H.H. Lester: Incorporation of $\left({ }^{4} \mathrm{C}\right)$-phenylalanine into flavan3-ols and procyanidins in cell suspension cultures of Douglas fir. Plant Physiol. 69, 1055-1059 (1982)

41. Stafford, H.A. \& H.H. Lester: Enzymic and nonenzymic reduction of (+)-dihydroquercetin to its 3,4-diol. Plant Physiol. 70, 695-698 (1982)

42. TANAKA, T., G-I. NONAKA \& I. NISHIOKA: 7-O-galloyl-(+)-catechin and 3-O-galloylprocyanidin B-3 from Sanguisorba officinalis. Phytochemistry 22, 2575-2578 (1983)

43. Wettstein, D. von, B. Jende-Strid, B. AhRenst-Larsen \& K. ERdal: Proanthocyanidin free barley prevents the formation of beer haze. MBAA Technical Quarterly 17, 16-23 (1980)

44. Zaprometov, M. \& H. GrisebaCh: Dihydrokaempferol as precursor for catechins in the tea plant. Z. Naturforsch. 28c, 113-115 (1973) 